\title{
Circadian Rhythms and Energy Metabolism Reprogramming in Parkinson's Disease
}

\author{
Alexandre Vallée ${ }^{1 *}$, Yves Lecarpentier ${ }^{2}$ \\ and Jean-Noël Vallée ${ }^{3,4}$
}

${ }^{1}$ Délégation à la Recherche Clinique et Industrielle (DRCl), Hôpital Foch, Suresnes, France

${ }^{2}$ Centre de Recherche Clinique, Grand Hôpital de I'Est Francilien (GHEF), Meaux, France

${ }^{3}$ Laboratory of Mathematics and Applications (LMA), UMR CNRS 7348, University of Poitiers, Poitiers, France

${ }^{4} \mathrm{CHU}$ Amiens Picardie, University of Picardie Jules Verne (UPJV), Amiens France

*alexandre.g.vallee@gmail.com

DOI: https://dx.doi.org/10.21775/cimb.031.021

\section{Abstract}

Entropy rate is increased by several metabolic and thermodynamic abnormalities in neurodegenerative diseases (NDs). Changes in Gibbs energy, heat production, ionic conductance or intracellular acidity are irreversible processes impelling modifications of the entropy rate. The present review focuses on the thermodynamic implications in the reprogramming of cellular energy metabolism enabling in Parkinson's disease (PD) through the contrasting interplay of the molecular signaling pathways WNT/ $\beta$-catenin and PPARY. In PD, WNT/ $\beta$-catenin pathway is downregulated while PPARY is upregulated. Thermodynamic behaviors of metabolic enzymes are modified by dysregulation of the canonical WNT/ $\beta$-catenin pathway. Downregulation of WNT/ $\beta$-catenin pathway leads to hypometabolism, oxidative stress and cell death through inactivation of glycolytic enzymes such as Glut, PKM2, PDK1, MCT-1, LDH-A but also to activation of PDH. In addition, in NDs, PPARy is dysregulated even though it contributes to the regulation of several key circadian genes. PD processes may be considered as dissipative structures that exchange energy or matter with their environment far-from the thermodynamic equilibrium. Far-from-equilibrium thermodynamics are notions driven by circadian rhythms, which directly contribute to regulation of the molecular pathways WNT/ $\beta$-catenin and PPARY involved in the reprogramming of cellular energy metabolism enabling in Parkinson's disease.

\section{Introduction}

Parkinson's disease (PD) is a major neurodegenerative disease with a progressive degeneration of neurons containing dopamine in the substantia nigra pars compacta. PD is triggered in brainstem or in the spinal cord of subjects who remain asymptomatic for a long time (Braak, Ghebremedhin, Rüb, Bratzke, and Del Tredici, 2004; Grinberg, Rueb, Alho, and Heinsen, 2010). While the primary etiology remains unknown, the presence of Lewy bodies (clumps of a-synuclein and ubiquitin proteins in neurons which are detectable in post-mortem brain histology) has observed from the earlier stages. PD is characterized by tremor symptom, rigidity, bradykinesia and postural instability. These symptoms occur only when the majority of dopaminergic cells is lost in the substantia nigra pars compacta, which means that the smooth, coordinated regulation of striatal motor circuits is also lost (Maguire-Zeiss and Federoff, 2010). Depression or rapid eye movement (REM)associated sleep behavior disorder (RBD) are nonmotor symptoms that could precede the onset of disease.

In most cases PD is an idiopathic form, but familial PD genes are often referred to as PARK genes. Indeed, mutations in PARK8, codifying for Leucinerich repeat kinase 2 (LRRK2), have been identified as a cause of familial Parkinson's (Häbig, Walter, Poths, Riess, and Bonin, 2008). No treatment can currently delay or stop the progression of $\mathrm{PD}$, and the medications currently available are mostly symptomatic.

Age is a major risk factor for neurodegenerative diseases (NDs). The aging process can perturb 
molecular pathways regulating cellular homeostatic mechanisms. Neurodegenerative cells are the sites of numerous energy abnormalities (Yin, Boveris, and Cadenas, 2014). The altered cells are derived from exergonic processes and emit heat that flows to the surrounding environment. Many irreversible processes can occur once the entropy rate has been modified. This rate represents a thermodynamic quantity that measures irreversible processes such as Gibbs energy, heat production, or ionic conductance (Kondepudi and Prigogine, 1999; Prigogine, 1986; Prigogine, Nicolis, and Babloyantz, 1974; Sandler, 2006). Several energy cellular mechanisms can induce and develop neurodegenerative processes. PD presents an energy and metabolic remodeling entailing increased oxidative stress and neuroinflammation (Kim, Kim, Rhie, and Yoon, 2015). This energy metabolism remodeling increase the entropy production rate in NDs (Riggs, 1998).

$W N T / \beta$-catenin signaling is a crucial factor in the development of many NDs (Libro, Bramanti, and Mazzon, 2016). Overexpression of GSK3 increases neurotoxicity via inactivation of $W N T / \beta$-catenin signaling, and activation of GSK3 is involved in neurodegeneration (Dun et al., 2012; WiedauPazos, Wong, Solomon, Alarcon, and Geschwind, 2009). Parkinson's disease (PD) presents downregulation of the canonical WNT/ $\beta$-catenin pathway (Libro et al., 2016). Inactivation of WNT/ $\beta$ catenin pathway leads to oxidative stress in mitochondria (Harris, Tindale, and Cumming, 2014). In parallel, peroxisome proliferator-activated $\mathrm{Y}$ (PPARY) is modified in neurodegenerative diseases. Targeting PPARy expression appears as an interesting therapeutic perspective against neurodegeneration (Esmaeili et al., 2016), and neuroinflammation, especially in PD (Pinto et al., 2016).

Some of the processes involved during NDs, such as WNT proteins (Goldbeter and Pourquié, 2008) and (PPARY) (Yves Lecarpentier, Claes, and Hébert, 2010), are considered as dissipative structures that exchange energy or matter with their environment. Dissipative structures are open systems which operate far-from a thermodynamic equilibrium and driven by circadian rhythms (CRs) (Goldbeter, 2017; Prigogine, 1986; Prigogine et al., 1974). Indeed, CRs are directly involved in regulation of the molecular open-system pathways found in NDs processes (Videnovic and Zee, 2015).
In numerous tissues, inhibition of the canonical $W N T / \beta$-catenin pathway is induced by the activation of PPARY, while activation of the canonical WNT/ $\beta$ catenin pathway induces inactivation of PPARY (Yves Lecarpentier, Claes, Duthoit, and Hébert, 2014; Siersbæk et al., 2012; N. Wang et al., 2008; $\mathrm{K}$. Zhang, Zhang, Han, Pu, and Kang, 2012). PD is characterized by downregulation of the canonical WNT/ $\beta$-catenin while PPARY is upregulated (Berwick and Harvey, 2012; J. Clark, Reddy, Zheng, Betensky, and Simon, 2011).

PPARy can regulate CRs through some key circadian genes, such as Bmal1 (brain and muscle aryl-hydrocarbon receptor nuclear translocator-like 1) (N. Wang et al., 2008). Dysfunction of PPARy can influence statistical mechanics by modifying thermodynamic force, thermodynamic flow, and rate of entropy production (Kondepudi and Prigogine, 1999; Y. Lecarpentier et al., 2008).

The opposite interplay between WNT/ $\beta$-catenin pathway and PPARy in PD plays a major role in both energy metabolism dysregulation and disruption of CRs. Thermodynamic dysregulation observed in PD is the consequence of an energy metabolism reprogramming induced by the dysfunction of the contrasting interplay between WNT/ $\beta$-catenin pathway and PPARY. We focused this review on the opposed interactions observed in PD between the canonical WNT/ $\beta$-catenin pathway and PPARY and their circadian rhythms and energy metabolism implications.

\section{Interplay between canonical WNT/ß-catenin pathway and PPARY}

\section{Canonical WNT/B-catenin pathway}

During embryogenesis, the Wingless/Int (WNT) pathway is involved in neural development and in adulthood in the maintenance of neuronal homeostasis (Harrison-Uy and Pleasure, 2012; Ille and Sommer, 2005; Oliva, Vargas, and Inestrosa, 2013; Salinas, 2012). It regulates synaptogenesis and synaptic function (Salinas, 2012).

WNT proteins belong to the family of secreted lipidmodified glycoproteins, present in different species (Al-Harthi, 2012). WNT ligands are activators of the WNT signaling stimulating intracellular WNT signaling. WNT ligands are secreted by both neurons and immune cells in the central nervous system (Marchetti and Pluchino, 2013). WNT family genes comprises 19 members which are classified as canonical WNTs and non-canonical WNTs. 
Canonical WNT ligands (WNT1, WNT2, WNT3, WNT8a, WNT8b, WNT10a, WNT10b) are activators of the WNT signaling which stimulate the intracellular WNT signaling (such as the betacatenin nuclear translocation), and secreted by both neurons and immune cells in the central nervous system (Marchetti and Pluchino, 2013). WNT ligands are cysteine rich proteins of approximately 350-400 amino acids that contain an N-terminal signal peptide for secretion since they are lipid modified secreted proteins (MacDonald, Tamai, and $\mathrm{He}, 2009)$.

Metabolism, embryonic development, cell fate, and epithelial-mesenchymal transition (EMT) are involved by the regulation of the WNT/ $\beta$-catenin pathway. Immunohistochemical staining and Western blotting can detect elevated levels of $\beta$ catenin in the nucleus and/or cytosol after WNT signaling activation. WNT pathway dysfunction is involved in numerous diseases, particularly in neurodegenerative diseases (Yves Lecarpentier et al., 2014; Yves Lecarpentier and Vallée, 2016; Vallée and Lecarpentier, 2016). The major key of the canonical WNT pathway is the $\beta$-catenin/T-cell factor/lymphoid enhancer factor (TCF/LEF) complex. After entered the nucleus, $\beta$-catenin engages DNA-bound TCF/LEF complex transcription factor. This association with $\beta$-catenin transiently converts TCF/LEF complex from a transcriptional repressor into an activator of specific target genes involved throughout development, cell survival and proliferation. In the absence of WNT ligands, TCF/LEF complex interacts with Groucho transcriptional repressors preventing genes transcription (Clevers and Nusse, 2012).

$\beta$-catenin accumulation is controlled by the destruction complex AXIN, tumor suppressor adenomatous polyposis coli (APC), and glycogen synthase kinase-3 (GSK3). In the absence of WNT ligands, the destruction complex provides a scaffold to allow GSK3 and CK1 (casein kinase 1) to phosphorylate $\beta$-catenin and then to generate its degradation into the proteasome. In the presence of WNT ligands, the latter interact with Frizzled (FZL) and LDL receptor-related protein 5/6 (LRP 5/6). This interaction disturbs the destruction complex and prevents $\beta$-catenin degradation into the proteasome by translocating it to the nucleus for interaction with TCF/LEF. This leads to the activation of $\beta$-catenin target genes (PDK1, MCT-1, C-Myc, cyclin D1, COX2, AXIN2) (Angers and Moon, 2009; He et al., 1998; Shtutman et al., 1999).
GSK3 and Dikkopf-1 (DKK1) are two major inhibitors of WNT/ $\beta$-catenin pathway signaling (Clevers and Nusse, 2012; Inestrosa, MontecinosOliva, and Fuenzalida, 2012; Rosi et al., 2010; Sharma, Pradeep, Wong, Rana, and Rana, 2004). DKK1, an antagonist of the WNT signaling (Semënov, Zhang, and He, 2008), binds to LRP5/6 co-receptors and then inhibits WNT signaling (Kawano and Kypta, 2003). Through a negative feedback loop, the $\beta$-catenin/TCF complex can regulate DKK1 transcription (Niida et al., 2004). GSK3 is a main negative regulator of the WNT pathway (Aberle, Bauer, Stappert, Kispert, and Kemler, 1997). As an intracellular serin-threonin kinase, GSK3 is involved in the regulation of several forms of pathophysiological signaling, including cell membrane signaling, neuronal polarity, and inflammation (Ambacher et al., 2012; Hur and Zhou, 2010; D. Wu and Pan, 2010). GSK3 acts through inhibition of $\beta$-catenin cytosolic stabilization and nuclear migration. Neuroinflammation is an agerelated process with increased GSK3 and decreased Akt and WNT/ $\beta$-catenin pathways in the hippocampus of older rats (Orellana et al., 2015). Akt regulates GSK3 activity by a direct phosphorylation S21 for GSK3- $\alpha$ and S9 for GSK3- $\beta$ $(H$. H. Zhang, Lipovsky, Dibble, Sahin, and Manning, 2006). Dysregulation of WNT/ $\beta$-catenin pathway is observed in NDs, with downregulation of WNT signaling appearing in PD (Libro et al., 2016).

\section{PPARY}

The ligand-activated transcriptional factor peroxisome proliferator receptor $\mathrm{Y}$ (PPARY) is a member of the nuclear hormone receptor super family. It forms a heterodimer with retinoid $X$ receptor (RXR), generating a PPARY-RXR complex for binding to specific peroxisome proliferator response element (PPRE) regions in the DNA and activating several target genes involved in fatty acid transport (FABP3), cholesterol metabolism (CYP7A1, LXRa, CYP27), glucose homeostasis (PEPCK, GyK) and lipid catabolism (SCD-1). This dimer interacts with other coactivators proteins such as PGC-1 $\alpha$, and induces specific genes expression (Ahmadian et al., 2013). Few endogenous ligands of PPAR gamma are known, these include fatty acids, phytanic acid, oxidized metabolites of linoleic acid, such as 9-hydroxy and 13-hydroxy octadecadienoic acids (9-HODE and 13-HODE); polyunsaturated fatty acids (arachidonic acid), and eicosanoids (Behl, Kaur, Goel, and Kotwani, 2016; GrygielGórniak, 2014). Anandamide, an endogenous cannabinoid receptor ligand binds PPAR gamma and induces differentiation of 3T3-L1 fibroblast cell 
of mice into adipocytes (Schild et al., 2002). However, the major endogenous ligand of PPAR gamma is 15-deoxy-delta 12, 14-prostaglandin J2 (15d-PGJ2) (Behl et al., 2016).

Glucose homeostasis, insulin sensitivity, lipid metabolism, immune responses, cell fate and inflammation are regulated by PPARy activation (Elbrecht et al., 1996; Fajas et al., 1997). PPARy is abundantly expressed in adipose tissue, whereas in heart, skeletal muscle and in liver PPARy is lower expressed (Bright, Kanakasabai, Chearwae, and Chakraborty, 2008). PPARy is little expressed in central nervous system (CNS) but present in several cell types such as neurons, astrocytes, oligodendrocytes and microglia (Braissant, Foufelle, Scotto, Dauça, and Wahli, 1996; Y.-C. Chen et al., 2012; Chiang et al., 2010, 2015). PPARy expression is localized mainly in the microglia and astrocytes and plays a major role in the inflammatory response of the CNS (Kapadia, Yi, and Vemuganti, 2008). In neurons, PPARy immunoreactivity appears mainly as a nuclear labeling, even though at times, cytoplasmic staining is detectable in cortical neurons (Chiang et al., 2015). Circadian variations of blood pressure and heart rate are regulated by PPARy through its action on Bmal1 (Yves Lecarpentier et al., 2010; N. Wang et al., 2008). PPARY modulates the expression of several genes involved in inflammation, and it decreases the activity of inflammation-related transcription factors such as NF-kappaB (Ricote and Glass, 2007).

PPARy expression and activity may be dysregulated during aging and be associated with loss of function (Haramizu, Ota, Hase, and Murase, 2011). PPARy agonists can prevent the metabolic effects of aginginduced neuroinflammation and neurodegeneration (Esmaeili et al., 2016). PPARy agonists induce neuroprotective effects in PD (Carta et al., 2011).

\section{Opposing effects between the canonical WNT/B- catenin pathway and PPARY}

WNT/ $\beta$-catenin pathway and PPARY act in an opposite manner. Functional interaction between $\beta$ catenin and PPARY involves a TCF/LEF domain of $\beta$-catenin and a catenin-binding domain within PPARy (Liu, Wang, Zuo, and Farmer, 2006; Lu and Carson, 2010; Sharma et al., 2004; Takada, Kouzmenko, and Kato, 2009). A previous study has shown that mutation of K312 and K435 in the TCF/ LEF binding domain of oncogenic S37 $\beta$-catenin decreases its ability to interact with and inhibit PPARY activity. Furthermore, these mutations render S37A $\beta$-catenin susceptible to proteasomal degradation in response to activation of PPARY. Mutation of F372 within the catenin-binding domain (helices 7 and 8 ) of PPARy disrupts its binding to $\beta$ catenin and reduces PPARY ability to induce the proteasomal degradation of $\beta$-catenin (Liu et al., 2006).

In several diseases when the WNT/ $\beta$-catenin pathway is downregulated, PPARY appears to be upregulated whereas when the WNT/ $\beta$-catenin is upregulated, PPARY appears to be downregulated (Yves Lecarpentier et al., 2014). This observation is also observed in arrthymogenic right ventricular cardiomyopathy (ARVC) (Djouadi et al., 2009; Garcia-Gras et al., 2006), hypertension (Vallée, Lévy, and Blacher, 2018), osteoporosis (Korvala et al., 2012), bipolar disorder (Valvezan and Klein, 2012), schizophrenia (Panaccione et al., 2013) and certain neurodegenerative diseases (NDs) such as Alzheimer's disease (Vallée and Lecarpentier, 2016; Vallée, Lecarpentier, Guillevin, and Vallée, 2017b, 2018c). Conversely, in other diseases, WNT/ $\beta$ catenin signaling is upregulated whereas PPARY is downregulated. This is the case in cancers (Yves Lecarpentier, Claes, Vallée, and Hébert, 2017b, 2017a; Vallée, Guillevin, and Vallée, 2017; Vallée, Lecarpentier, Guillevin, and Vallée, 2017e), lymphomas (Vallée, Lecarpentier, and Vallée, 2019), type 2 diabetes (Yves Lecarpentier et al., 2017a), and certain NDs, such as amyotrophic lateral sclerosis (Yves Lecarpentier and Vallée, 2016; Vallée, Lecarpentier, Guillevin, and Vallée, 2018a), Huntington's disease (Godin, Poizat, Hickey, Maschat, and Humbert, 2010; Vallée, Lecarpentier, et al., 2018a), exudative AMD (Vallée, Lecarpentier, Guillevin, and Vallée, 2017d, 2017a), multiple sclerosis (Vallée, Lecarpentier, Guillevin, and Vallée, 2018b; Vallée, Vallée, Guillevin, and Lecarpentier, 2017), fibrosis processes (Vallée, Lecarpentier, Guillevin, and Vallée, 2017c; Vallée, Lecarpentier, and Vallée, 2017), autism (Vallée, Vallée, and Lecarpentier, 2018) and Friedreich's ataxia (Coppola et al., 2009). The activation of PPARy can be induced by inhibition of the WNT/ $\beta$-catenin pathway (Garcia-Gras et al., 2006) while PPARy agonists can inhibit $\beta$-catenin in several cellular systems (Elbrecht et al., 1996; Fajas et al., 1997; Moldes et al., 2003). PPARy agonists could act through WNT/ $\beta$-catenin/PI3K/Akt pathway as neuroprotective agents and promote synaptic plasticity (Farshbaf, Ghaedi, Shirani, and NasrEsfahani, 2014). The WNT pathway increases methyl-CpG binding protein 2, which represses PPARY and activates hepatic stellate cells. Crosstalk between PPARY and WNT signaling is 
also observed in the regulation of mesenchymal stem cell differentiation (Xu et al., 2016).

\section{Downregulation of the canonical WNT/ $\beta$-catenin pathway and upregulation of PPARY in PD.}

\section{Downregulation of the canonical WNT/B-catenin pathway (Table 1)}

Abnormalities of WNT signaling are implicated in PD (Parish et al., 2008; Rawal et al., 2009). Dysregulation of WNT signaling is considered as an initiating event in the development of PD (Berwick and Harvey, 2012). Several cell biological functions affected in PD are controlled by the WNT signaling pathway, such as microtubule stability, axonal function and membrane trafficking (Berwick and Harvey, 2011; Inestrosa and Arenas, 2010). The mesencephalic dopaminergic neuron-astrocyte crosstalk is controlled by WNT1 regulated Frizzled-1/ $\beta$-catenin signaling pathway (L'episcopo et al., 2011). DKK1 and GSK3, two inhibitors of the WNT pathway, increase in PD (Zhou et al., 2016). PD mouse model show a crosstalk between inflammatory and $\mathrm{WNT} / \beta$-catenin signaling pathway (L'Episcopo et al., 2012). In normal circumstances, LRRK2 interacts with WNT family with the Disheveled (DSH) proteins. This interaction inhibits the $\beta$-catenin destruction complex to promote the activation of the canonical WNT pathway (Berwick and Harvey, 2012). In family forms of PD, LRRK2 mutations can reduce the LRRK2-LRP5/6 binding affinity and are associated with reduced activation of canonical WNT pathway (Libro et al., 2016). PARKIN is an E3 ubiquitin ligase encoded by the
PARK2 gene. PARKIN genetic alterations are implicated in family PD development and act as $\beta$ catenin repressors promoting $\beta$-catenin ubiquitination and degradation (Rawal et al., 2009).

\section{Upregulation of PPARY (Table1)}

Chronic inflammation is one of the hallmarks of PD with increased pro-inflammatory factor levels in substantia nigra (Hirsch, Vyas, and Hunot, 2012; Q. Wang, Liu, and Zhou, 2015). The PPARY ligand 15deoxy-ProstaglandinJ2 production is enhanced by stress, which increases expression of PPARy in cerebral cortex to counteract inflammation and oxidative stress (García-Bueno et al., 2005). Inflammation and oxidative consequences of stress exposure may be prevent by PPAR ligands (GarcíaBueno et al., 2005) through an action of neuroprotection mediator (Galea, Heneka, Dello Russo, and Feinstein, 2003). The main neuroprotection action of PPARY agonists consists in their anti-inflammatory activity (Carta et al., 2011). In rat nigro-striatal system, the degeneration of dopaminergic neurons is induced by nonphysiological overexpression of PGC-1a (Ciron, Lengacher, Dusonchet, Aebischer, and Schneider, 2012).

\section{Brain energy metabolism}

Energy is the main determinant of neuronal viability. Under normal physiological conditions, adult brain uses exclusively glucose for energy metabolism (S.$\mathrm{H}$. Yang et al., 2015). Glucose is almost metabolized to $\mathrm{CO} 2$ and water through glycolysis, tricarboxylic acid (TCA) cycle, and mitochondrial oxidative

Table 1. Role of the WNT and PPARY in PD.

\begin{tabular}{|ll|}
\hline WNT pathway in PD & Reference \\
\hline PARKIN inhibits WNT & Rawal et al., 2009 \\
Inhibited WNT enhances hypometabolism and mitochondrial dysfunction & Mosconi et al., 2008 \\
Inhibited WNT reduces activity of PI3K/Akt pathway & Yu et al., 2010 \\
Reduced PI3K/Akt participates to PD progression & Heras-Sandoval et al. 2014 \\
Inhibited WNT stimulates ROS production & Blesa et al., 2015 \\
Dysregulation of CRs inhibits WNT pathway & Sahar and Sassone-Corsi, 2009 \\
\hline PPARy in PD & References \\
\hline PPARY controls oxidative phosphorylation & Tsunemi et al., 2012 \\
PPARY represses neuroinflammation & Corona and Duchen, 2015 \\
PPARy inhibits oxidative stress & Pinto et al.,2016 \\
Pioglitazone increases neuronal glucose uptake & Rong et al., 2011 \\
PPAR agonist can regulate CRs genes & Yang et al., 2012 \\
\hline
\end{tabular}


phosphorylation (Bélanger, Allaman, and Magistretti, 2011). In the presence of oxygen, glycolysis is coupled with TCA cycle and mitochondrial oxidative phosphorylation. Cytosolic lactate is shuttled out of the cell through monocarboxylate transporter (MCT) for oxidation to obtain pyruvate. Pyruvate is converted into many organic acids through TCA cycle (Schurr, 2014). TCA cycle reduces NDA+ to $\mathrm{NADH}$ into mitochondrial oxidative phosphorylation to generate ATP, the ultimate biochemical energy. Dysfunction of mitochondrial dynamics has been observed in NDs and cancers $(\mathrm{H}$. Chen and Chan, 2009; Grandemange, Herzig, and Martinou, 2009). Mitochondrial oxidative phosphorylation is considered as the major metabolic pathway in brain. Aerobic glycolysis predominates in the developing brain during embryogenesis (Bauernfeind et al., 2014), while there is progressively a shift from aerobic glycolysis to oxidative phosphorylation from embryogenesis to late adulthood within the human brain (Barros, 2013; Harris et al., 2014). Mitochondrial oxidative phosphorylation allows brain glucose to fuel neuronal activity (Simpson, Carruthers, and Vannucci, 2007). The single largest glucose reserve glycogenesis predominately localizes in astrocyte end-feet, bodies and processes (DiNuzzo, Maraviglia, and Giove, 2011; Oz et al., 2007). Astrocytes can mobilize glycogen for neuronal metabolism under normal circumstances, and under increased energy demand or failure of neurons (S.-H. Yang et al., 2015). But, due to low content of glycogen in brain as compared to liver and skeletal muscles, astrocytic glycogen is unlikely to serve as an alternative energy supply during hypoglycemia. Thus brain metabolism under normal conditions uses astrocytic glycogen as an integral source of energy (DiNuzzo et al., 2011; Obel et al., 2012). Astrocytes may play a major role in bioenergetics and biosynthetic metabolism in the brain while pyruvate derived from neuronal glucose is considered as the main fuel for neurons (Patel et al., 2014). NDs show dysfunctions of astrocyte metabolism (Stobart and Anderson, 2013). The causal role of mitochondrial dysfunctions in aging and age-related NDs has been shown by abundant evidence (Bratic and Larsson, 2013; H. Chen and Chan, 2009; S.-H. Yang et al., 2015).

\section{Energy metabolism disorders in Parkinson's disease}

\section{Cerebral hypometabolism in PD}

PD brain shows reduction in its glucose metabolism (Borghammer, 2012; Borghammer et al., 2010;
Dunn et al., 2014). Glucose hypo-metabolism has been found in cerebral cortex in PD patients with and without dementia (Edison et al., 2013). Symptom severity is temporally correlated with cerebral hypo-metabolism, which can be considered as a predictive value for onset of dementia (Mosconi, Pupi, and De Leon, 2008). Mitochondrial dysfunctions have also been observed in PD brains by increasing production and releasing reactive oxygen species (ROS) (Franco-lborra, Vila, and Perier, 2016). Such mitochondrial defects cause cell damage and death by energy depletion due to the disruption of oxidative phosphorylation (LuqueContreras, Carvajal, Toral-Rios, Franco-Bocanegra, and Campos-Peña, 2014). Oxidative stress and mitochondrial dysfunction increase cell death and dementia (Benilova, Karran, and De Strooper, 2012; Islam, 2017; Sochocka, Koutsouraki, Gasiorowski, and Leszek, 2013).

\section{Donwregulation of WNT pathway involves cerebral hypometabolism in PD (Figure 1)}

Downregulation of the canonical WNT/ $\beta$-catenin pathway inhibits $\beta$-catenin target genes (PDK1, MCT-1, c-Myc, cyclin D1, LDH-A) which contribute to regulation of glucose metabolism (Angers and Moon, 2009; He et al., 1998; Shtutman et al., 1999). PARKIN deficiency leads to mitochondrial dysfunctions in neuronal cells, and contribute to progression of family forms of PD (Palacino et al., 2004; Pesah et al., 2004) by inhibiting the WNT/ $\beta$ catenin pathway (Rawal et al., 2009).

Downregulation of $\beta$-catenin also reduces the activity of PI3K/Akt pathway (Park et al., 2004; Yue et al., 2010). PI3K/Akt pathway is downregulated in PD humans brain (Heras-Sandoval, Pérez-Rojas, Hernández-Damián, and Pedraza-Chaverri, 2014). HIF-1a, a downstream target of PI3K/Akt pathway (Sun et al., 2011), is responsible for the expression of enzymatic enzymes such as Glut, LDH-A, PDK1 and PKM2 (Semenza, 2010; Sun et al., 2011). Inactivation of HIF-1a induces PKM2 nontranslocation to the nucleus, which induces PKM2 inhibition on PEP cascade and the formation of pyruvate. $\beta$-catenin is not binding by PKM2, and glycolytic enzymes (Glut, LDH-A, PDK1) are not activated because of non-formation of c-Myc/PKM2 complex. In conclusion, downregulation of WNT/ $\beta$ catenin decreases PI3K/Akt activity and its downstream targets such as HIF-1a, Glut, PKM2, PDK1, and LDH-A. This phenomenon leads to glucose hypometabolism and mitochondrial dysfunction increasing symptom severity and may 


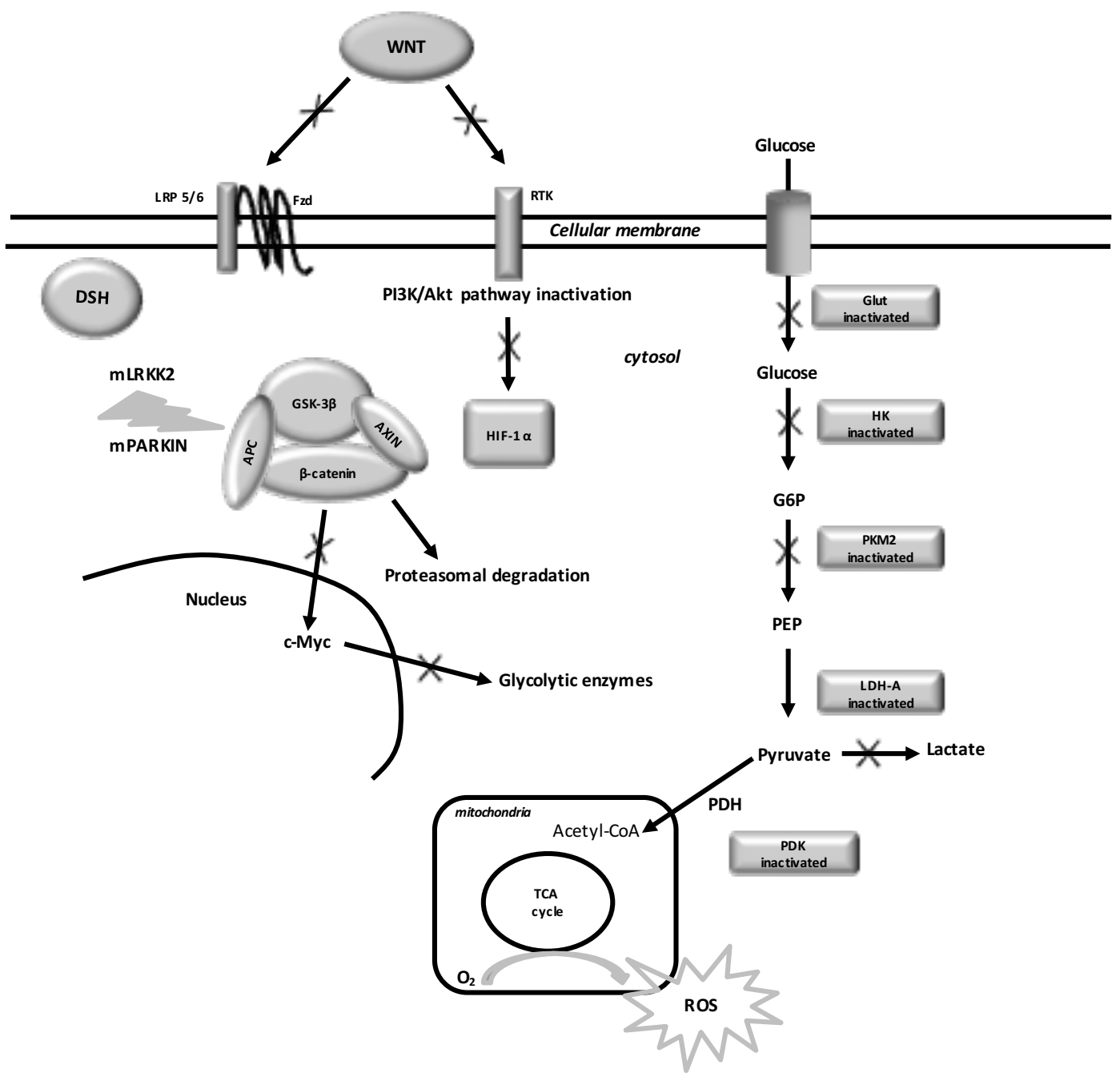

Figure 1. Cerebral hypometabolism and downregulation of the WNT/ $\beta$-catenin pathway in PD. In PD, mutant PARKIN and mutant LRRK2 activate $\beta$ catenin destruction complex. AD and PD lead to WNT "off state". DSH dissociates from FZD and AXIN. APC and AXIN complex with GSK3. B-catenin is phosphorylated, dissociates from GSK3, migrates to the cytosol and is destroyed in the proteasome. Natural decline in glycolysis is associated with old age. Inhibition of WNT/B-catenin decreases PI3/Akt pathway and inhibits levels of HIF-1a. Decreased HIF-1a activity reduces expression of glycolytic enzymes (GLUT, HK, PKM2, LDH-A, PDK) and increases metabolic flux through mitochondrial respiration. Decreased activity of PKM2 reduces its translocation to the nucleus and its activation of glycolytic genes. Cellular respiration produces large amounts of ROS and thereby induces apoptosis. Downregulation of WNT pathway leads to decreased glucose metabolism and to the increased of oxidative stress associated with ROS.

appear as a predictive value for onset of dementia (Mosconi et al., 2008).

\section{Oxidative stress in PD}

Development of PD is associated with the initiation of oxidative stress (Kim et al., 2015). Reduction of the respiratory chain activity in substantia nigra pars compacta of PD patients generates excessive ROS and induces apoptosis (Blesa, Trigo-Damas, Quiroga-Varela, and Jackson-Lewis, 2015; Franco-
Iborra et al., 2016; Schapira, 2008). In family forms of PD, mitochondrial dysfunction and oxidative stress are caused by mutations in PARKIN and PINK1 (Blesa et al., 2015). PINK1 mutations lead to mitochondrial defects and respiratory chain abnormalities (Hoepken et al., 2007), while PINK1 knockout increases ROS generation (WoodKaczmar et al., 2008). PINK1 and PARKIN can regulate mitochondrial function and cell survival in which PINK1 seems to be functioning upstream of 
PARKIN in Drosophilia disease models (I. E. Clark et al., 2006). To conclude, PARKIN and PINK1 both influence the risk of certain forms of mutated PD (Schapira, 2008; Thomas and Beal, 2007).

\section{Oxidative stress and PPARY in PD}

PPARY and PGC-1a control oxidative phosphorylation, antioxidant defense, and autophagy (StPierre et al., 2003; Tsunemi et al., 2012). PPARy agonists repress microglial activation and reduce neuroinflammation by inhibiting the expression of TNF- $\alpha$, COX2 and iNOS. PPARY agonists increase PGC-1 $\alpha$, which induces the downstream target genes involved in mitochondrial biogenesis, and then inhibit mitochondrial dysfunction, oxidative stress, neuroinflammation, apoptosis and increase expression of mitochondrial proteins and oxidative phosphorylation capacity (Corona and Duchen, 2015; Pinto et al., 2016; Wenz, Diaz, Spiegelman, and Moraes, 2008). In PD mouse brain, the PPARy agonist rosiglitazone, induces mitochondrial biogenesis and glucose utilization (Strum et al., 2007). Also in PD, pioglitazone, a PPARy agonist, increases neuronal glucose uptake, restores brain ATP levels, oxygen consumption, and increases PGC-1 $\alpha$ expression (García-Bueno, Caso, PérezNievas, Lorenzo, and Leza, 2007; Ghosh et al., 2007; Rong et al., 2011).

\section{Circadian rhythms (CRs) and circadian clock genes (Figure 2)}

Several biologic processes in the body are controlled by the circadian "clock" (circadian locomotors output cycles kaput). The circadian clock is in the hypothalamic suprachiasmatic nucleus (SCN). CRs are endogenous and entrainable freerunning periods that last approximately 24 hours. Several transcription factors are responsible for the regulation of CRs. They are named circadian locomotors output cycles kaput (Clock), brain and muscle aryl-hydrocarbon receptor nuclear translocator-like 1 (Bmal1), Period 1 (Per1), Period 2 (Per2), Period 3 (Per3), and Cryptochrome (Cry 1 and Cry 2) (Gekakis et al., 1998; Hogenesch, Gu, Jain, and Bradfield, 1998). These transcription factors are subject to positive and negative selfregulation mediated by CRs (Reppert and Weaver, 2002; Schibler and Sassone-Corsi, 2002). Clock and Bmal1 heterodimerize and then initiate transcription of Per1, Per2, Cry1 and Cry2 (Ko and Takahashi, 2006). The Per/Cry heterodimer can inhibit its activation through negative feedback. Its translocates back to the nucleus to directly repress the Clock/Bmal1 complex and then inhibits its own transcription (Ko and Takahashi, 2006).
Clock/Bmal1 heterodimer also activates the transcription of retinoic acid-related orphan nuclear receptors, Rev-Erbs and retinoid-related orphan receptors (RORs). Through positive feedback RORs can activate the transcription of Bmal1, whereas Rev-Erbs can repress their transcription through negative feedback (Ko and Takahashi, 2006).

\section{CRs, dissipative structures}

Changes in the balance of CRs is directly due to negative feedback produced by a protein on the expression of its own gene (Goodwin, 1965; Hardin, Hall, and Rosbash, 1990). In addition, CRs are dissipative structures and operate in far-fromequilibrium manner. They spontaneously exchange energy with their external environment and thereby change the entropy rate production of cells (Goldbeter, 2002; Prigogine et al., 1974). Several physiological and metabolic functions, such as heart rate, blood pressure, body temperature, sleepawake, and feeding patterns, are regulated by CRs (Sahar and Sassone-Corsi, 2009). Similarly, energy metabolism is also governed by CRs. The freeenergy dissipation per period has a regulated role on the phase diffusion constant and is proportional to the number of phase coherent periods. ATP is hydrolyzed by multiple irreversible cycles driven by oscillation (Cao, Wang, Ouyang, and Tu, 2015).

\section{CRs and aging}

Several studies have shown that the core clock machinery is obviously present not only in the SCN, but also in neurons and astrocytes (Abe et al., 2002; Marpegan et al., 2011). Circadian dysfunction occurs in the pathogenesis of aging and several diseases, such as cancers and chronic diseases (Anea et al., 2009; Bass and Takahashi, 2010; Evans and Davidson, 2013). Aging is marked by changes in the circadian system (Videnovic and Zee, 2015). Aging is characterized by changes in circadian rhythmicity with reduced amplitude, increased intra-daily variability, and decreased interdaily stability of circadian rhythms (Czeisler et al., 1992; Duffy et al., 2002; Hofman, 2000).

\section{Circadian rhythms, WNT/B-catenin pathway and PPARY (Figure 3)}

\section{CRs and WNT/ $\beta$-catenin pathway}

$W N T / \beta$-catenin pathway is downstream of the RORs regulation factors and possesses divers putative Bmal1 clock-binding sites within its promoter (T. L. Chen, 2004). Through these interactions, circadian genes can control cell cycle progression via the 


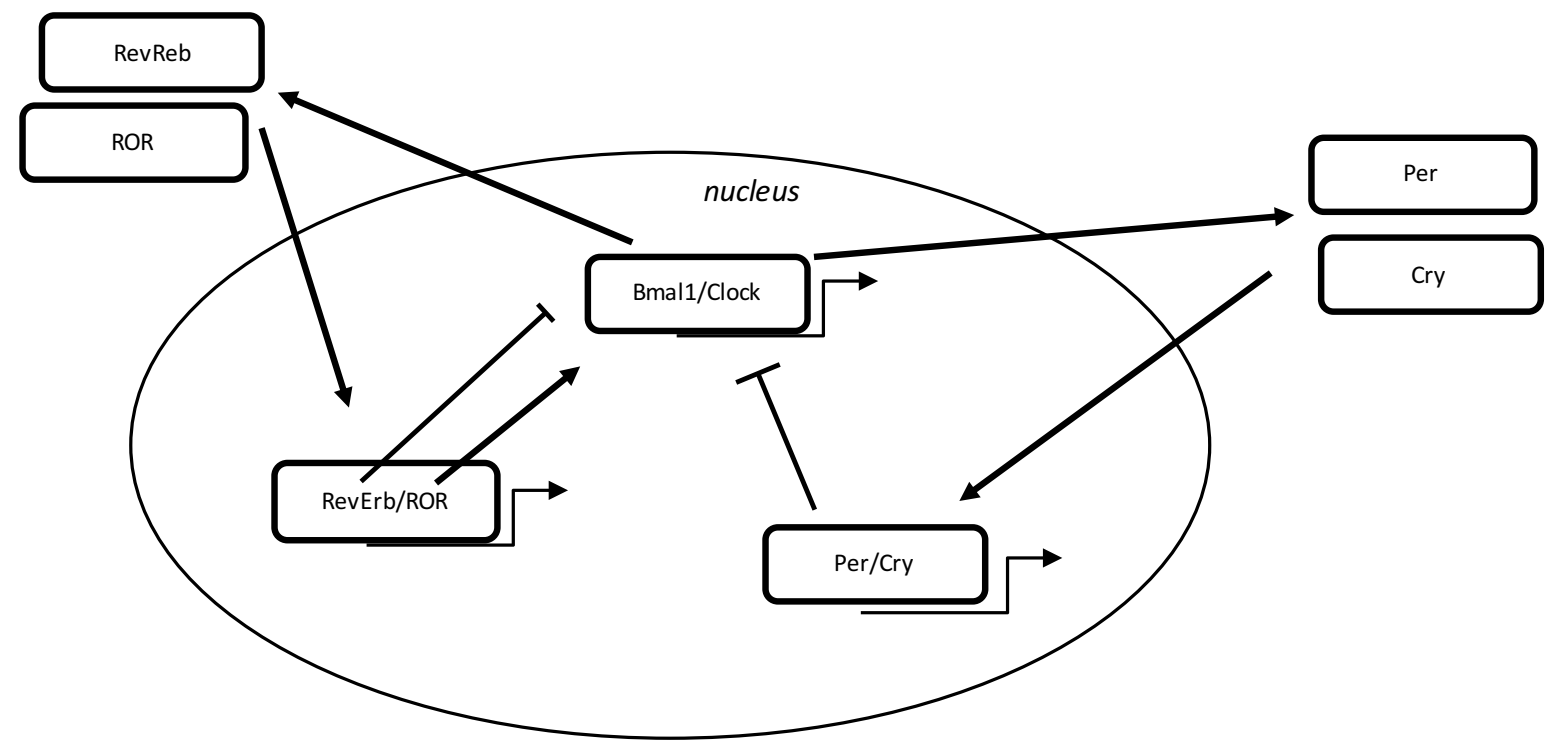

Figure 2. Circadian clock genes mechanism. The clock consists of a stimulatory loop, with the Bmal1/Clock heterodimer stimulating the transcription of Per and Cry genes, and an inhibitory feedback loop with the Per/Cry heterodimer translocating to the nucleus and repressing the transcription of the Clock and Bmal1 genes. An additional loop involves the RORs and RevErbs factors with a positive feedback by ROR and a negative feedback by RevErbs.

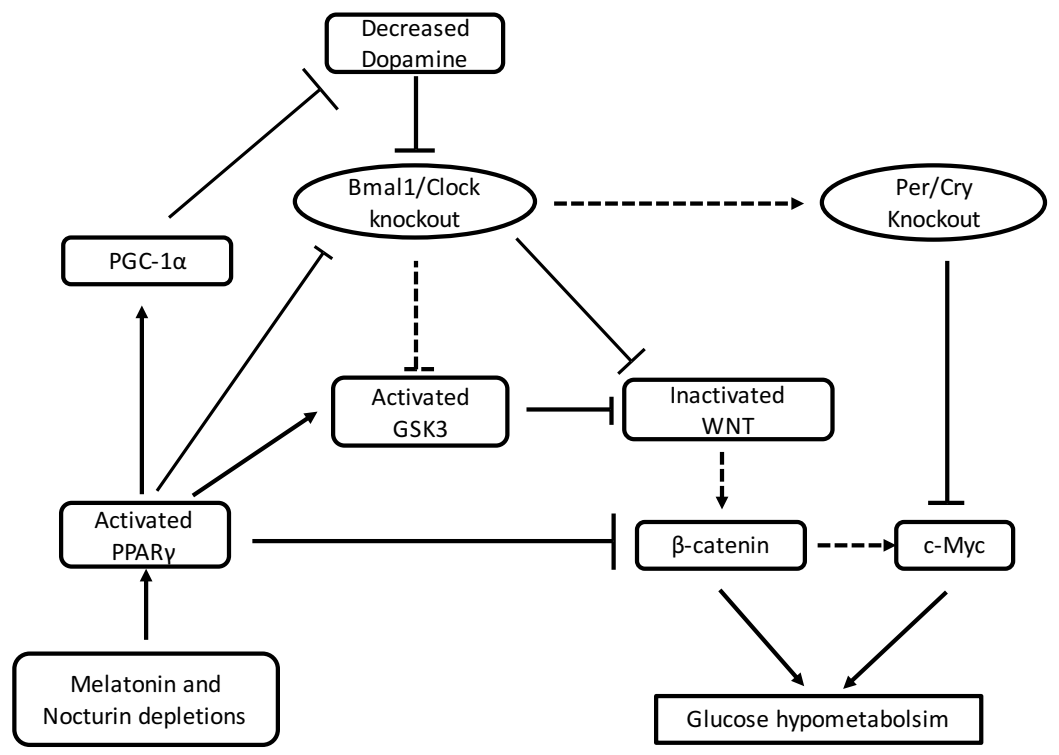

Figure 3. Interactions between PPARy, WNT pathway and circadian rhythms in PD. Depletions of melatonin and nocturin increase the expression of PPARy in PD. Increased PPARy stimulates the expression of PGC-1a to decrease the expression of Dopamine leading to Bmal1/Clock heterodimer knockout. Increased PPARy expression directly inhibits the formation of the heterodimer Bmal1/Clock and $\beta$-catenin cytosolic accumulation but increases the activity of GSK3, the main inhibitor of the WNT/B-catenin pathway. Bmal1/Clock knockout also increases GSK3 activity and inhibits the WNT/B-catenin pathway and its downstream gene c-Myc through the knockout of the heterodimer Per/Cry. The inhibition of the WNT/ $\beta$-catenin pathway by the degradation of the cytosolic $\beta$-catenin and the inactivation of c-Myc leads to glucose hypometabolism in PD. 
WNT pathway (Soták, Sumová, and Pácha, 2014). Expression and activity of the WNT signaling pathway can be inhibited by a Bmal1 knockdown (Guo et al., 2012). Expression levels of WNT-related genes in wild-type mice is higher than levels of WNT-related genes with Bmal1 knockdown mice (Janich et al., 2011; Yasuniwa et al., 2010). Cell proliferation and cell cycle progression are regulated by Bmal1 via the stimulation of the canonical WNT/ $\beta$-catenin pathway (Lin, Chen, Li, Zhao, and Tan, 2013). Bmal1 can enhance $\beta$-catenin transcription, reduce $\beta$-catenin degradation and repress GSK3 expression (Sahar and Sassone-Corsi, 2009). Per2 degradation induced by $\beta$-catenin involves circadian dysregulation in intestinal mucosa of ApcMin/+ mice (Xiaoming Yang et al., 2009). Per1 and Per2 maintain cells circadian rhythm and regulate cellrelated genes expression such as c-Myc (Duffield et al., 2002; Sancar, Lindsey-Boltz, Unsal-Kaçmaz, and Linn, 2004).

\section{CRs and PPARY}

PPARy interacts with the mammalian clock and energy metabolism (L. Chen and Yang, 2014). PPARy directly interacts with the core clock genes and presents diurnal variations in liver and blood vessels (N. Wang et al., 2008; Xiaoyong Yang et al., 2006). In mice, impaired diurnal rhythms are caused by a deletion of PPARY (G. Yang et al., 2012). Circadian metabolism is directly regulated by PPARY (G. Yang et al., 2012). PPARy agonists can control Bmal1 expression and formation of the heterodimer Clock/Bmal1 (H.-M. Wang et al., 2010; N. Wang et al., 2008) and can target Rev-Erb (Fontaine et al., 2003). Diminution of the clock controlled gene Nocturin decreases PPARy oscillations in the liver of mice fed on high-fat diet. Under normal conditions, Nocturin binds PPARy to improve its transcriptional activity (Green et al., 2007). PPARy deletion impacts circadian function of 15-Deoxy-D 12,14-prostaglandin J2 (15-PGJ2) (G. Yang et al., 2012). The partner of PPARY, RXR, acts on Clock protein in a ligand-dependent manner and then inhibits Clock/Bmal1 heterodimer formation and transcriptional activity (L. Chen and Yang, 2014).

\section{CRs and oxidative stress}

In Drosophila, disruption of Per involves a dysregulation of oxidative stress marker levels with circadian oscillations (Beaver et al., 2012). Per deletion exacerbates oxidative injury and shortens lifespan (Krishnan, Davis, and Giebultowicz, 2008; Krishnan, Kretzschmar, Rakshit, Chow, and Giebultowicz, 2009). Flies bearing a carbonyl reductase mutation show Per deletion, which accelerates neurodegeneration and causes oxidative injury to neurons (Krishnan et al., 2008). High levels of oxidative damage in the cortex and neurodegeneration are associated with Bmal1 knockout (Musiek, 2015). Bmal1 directly regulates the transcription of several important redox defense genes in the brain, including Nqo1 and Aldh2 (Musiek, 2015).

\section{Melatonin and neurodegeneration}

Melatonin (also named 5-methoxy- $\mathrm{N}$-acetyltryptamine) is a natural secreted by the pineal gland (Csernus and Mess, 2003). Melatonin synthesis regulates the modulation of sleep (Dubocovich, 2007; Pevet and Challet, 2011). Its released is observed during darkness and thereby contributes to the circadian regulation of sleep (Crowley and Eastman, 2013; Mauriz, Collado, Veneroso, Reiter, and González-Gallego, 2013). Reduction of the amplitude of melatonin rhythms is associated with aging (Duffy et al., 2002; Y.-H. Wu and Swaab, 2005), and its dysregulation has been observed in several neurodegenerative diseases (Cardinali, Pagano, Scacchi Bernasconi, Reynoso, and Scacchi, 2013).

Melatonin has anti-inflammatory, anti-oxidant and neuroprotective effects (Calvo, González-Yanes, and Maldonado, 2013; Galano, Tan, and Reiter, 2013; Mauriz et al., 2013; Rosales-Corral et al., 2012, p.; X. Wang et al., 2011; H.-M. Zhang and Zhang, 2014). Melatonin decreases phosphorylation of GSK3 (Giese, 2009; Hoppe et al., 2010). Melatonin controls PPARY expression, restores mitochondrial membrane potential, stimulates the biogenesis of mitochondria (Guven, Taskin, and Akcakaya, 2016) and enhances mitochondrial function (Kato et al., 2015).

\section{Parkinson's disease and circadian rhythms}

Several studies have underlined a relationship between circadian rhythms and PD development (Abbott et al., 2005; Gao et al., 2011; Weishaupt et al., 2006). Low peak activity levels and low amplitude of the rest-activity cycle are observed in PD patients (Videnovic and Zee, 2015). In PD, increase of physical activity levels and shorter periods of immobility during the night, result in a diurnal motor activity without oscillations (Videnovic and Zee, 2015).

Dopamine, by activation of the DR22 receptors, regulates the rhythm of clock protein Per2 expression (Hood et al., 2010; Videnovic and 
Golombek, 2013). Striatal dopamine regulates Bmal1/Clock heterodimer activity (Yujnovsky, Hirayama, Doi, Borrelli, and Sassone-Corsi, 2006) in a receptor dependent manner (Imbesi et al., 2009). Dopaminergic receptors and TH (Tyrosine hydroxylase), the enzyme responsible for the synthesis of dopamine (Parekh, Ozburn, and McClung, 2015), exhibit daily fluctuations.

Circadian disorders can accelerate the neuropathology of PD (Lauretti, Di Meco, Merali, and Praticò, 2017), although PD reveals progressive deterioration in motor function with day-to-day progression (Bonuccelli et al., 2000; Piccini et al., 1991) insomuch as PD circadian fluctuations underline dysregulations in motor performance and visual performance (Struck, Rodnitzky, and Dobson, 1990). Blood pressure and heart rate alterations are common in PD. Elevations of blood pressure and heart rate occur during the light phase and decrease during the dark phase of the light/dark cycle ( $L$. Chen and Yang, 2014). Sympathetic activity during the day decreases with a loss of circadian heart rate variability and a decrease of the sympathetic morning peak in melatonin in PD (Devos et al., 2003). PD patients show an elevation of cortisol levels, reduction of melatonin levels, and alteration of Bmal1 expression (Breen et al., 2014). Levels of Per1 and Cry1 diminish in Rotenone model of PD (Mattam and Jagota, 2015), whereas administration of melatonin results in restoration of Per1 levels but not on Cry and Bmal1 (Mattam and Jagota, 2015). The hypothalamic-pituitary-adrenal (HPA) axis is modulated by the circadian system and can be restored by promotion of normal dopamine function (Mizobuchi, Hineno, Kakimoto, and Hiratani, 1993).

Dopamine regulates circadian rhythmicity at molecular and behavioral levels (Videnovic and Willis, 2016). Depletion of dopamine by 6hydroxydopamine (6-OHDA) injection into medial forebrain results in decreased dorsal striatum Per2 level in rats (Hood et al., 2010). Per2 rhythms are restored by the activation of D2 receptors in the DAdepleted striatum (Gravotta, Gavrila, Hood, and Amir, 2011). Bmal1 is reduced during dark span in $\mathrm{PD}$, and Bmal1 levels are positively correlated with PD severity (Cai, Liu, Sothern, Xu, and Chan, 2010). Altered Bmal1 levels in PD are associated with dopamine depletion may be due to its capacity to regulate Bmal1/Clock heterodimer activity (Breen et al., 2014; Yujnovsky et al., 2006). This mean that dopamine depletion may directly affect the central component of the molecular clock and circadian disruption, which can accelerate PD progression (Kondratova and Kondratov, 2012).

\section{Conclusion}

Changes in entropy production rates are associated with metabolic and thermodynamic alterations and abnormal circadian rhythms in NDs. In PD, the canonical WNT/ $\beta$-catenin pathway is downregulated, while PPARy is upregulated. These two systems act in an opposed and reverse manner. From a thermodynamic point of view, ND processes are like many irreversible processes which can occur by changing the entropy production rate. Thermodynamic behaviors of metabolic enzymes in $\mathrm{PD}$ are modified by the dysregulation of both the canonical WNT/ $\beta$-catenin pathway and PPARY expression. Downregulation of $W N T / \beta$-catenin pathway results in inhibition of c-Myc, HIF-1 $\alpha$, PDK, LDH-A, and MCT-1. This explains the glucose hypometabolism and the stimulation of oxidative stress observed in PD cells. In parallel, PPARy interfere with the mammalian clock and energy metabolism and could be a promising therapeutic way in PD due to these interactions. PD processes may be considered as dissipative structures, which exchanges energy or matter with their environment. WNT pathway and PPARY are open systems, farfrom the thermodynamic equilibrium that operate under non-linear regime evolving to non-stationary states. Far-from-equilibrium thermodynamics are notions driven by circadian rhythms. Indeed, CRs directly contribute to regulation of the molecular pathways WNT/ $\beta$-catenin pathway and PPARY involved in the reprogramming of cellular energy metabolism enabling Parkinson's disease.

\section{Author contributions}

All authors listed have contributed to the work, and approved it for submitting to publication.

\section{Conflict of Interest statement}

The authors declare that the research was conducted in the absence of any commercial or financial relationship that could be construed as a potential conflict of interest.

\section{Abbreviations \\ Acetyl-coA: Acetyl-coenzyme; APC: Adenomatous polyposis coli; ARVC: Arrthymogenic right ventricular dysplasia/cardiomyopathy; Bmal1: Brain and muscle aryl-hydrocarbon receptor nuclear translocator-like 1; Clock: Circadian locomotor output cycles kaput; COX-2: Cyclooxygenase-2; Cry: Cryptochrome; DSH: Disheveled; EMT: Epithelial-mesenchymal transition; FZD: Frizzled;}


GK: Glucokinase; GLUT: Glucose transporter; GSK3: Glycogen synthase kinase-3; HD: Huntington's disease; LDH: Lactate dehydrogenase; LRP 5/6: Low-density lipoprotein receptor-related protein 5/6; MCT-1: Monocarboxylate lactate transporter-1; NDs: Neurodegenerative diseases; PD: Parkinson's disease; Per: Period; PPARY: Peroxisome proliferator-activated receptor $\mathrm{Y}$; PGC-1a: Peroxisome proliferator-activated receptory coactivator-1 $\alpha$; PI3K-Akt: Phosphatidylinositol 3kinase-protein kinase B; PFK-1: Phosphofructokinase-1; PDH: Pyruvate dehydrogenase complex; PDK: Pyruvate dehydrogenase kinase; RORs: retinoid-related orphan receptors; TCF/LEF: T-cell factor/lymphoid enhancer factor; TZD: Thiazolidinedione; TCA: Tricarboxylic acid.

\section{References}

Abbott, R. D., Ross, G. W., White, L. R., Tanner, C. M., Masaki, K. H., Nelson, J. S., ... Petrovitch, H. (2005). Excessive daytime sleepiness and subsequent development of Parkinson disease. Neurology, 65(9), 1442-1446. https://doi.org/ 10.1212/01.wnl.0000183056.89590.0d

Abe, M., Herzog, E. D., Yamazaki, S., Straume, M., Tei, H., Sakaki, Y., ... Block, G. D. (2002). Circadian rhythms in isolated brain regions. The Journal of Neuroscience: The Official Journal of the Society for Neuroscience, 22(1), 350-356.

Aberle, H., Bauer, A., Stappert, J., Kispert, A., and Kemler, R. (1997). $\beta$-catenin is a target for the ubiquitin-proteasome pathway. The EMBO Journal, 16(13), 3797-3804. https://doi.org/ 10.1093/emboj/16.13.3797

Ahmadian, M., Suh, J. M., Hah, N., Liddle, C., Atkins, A. R., Downes, M., and Evans, R. M. (2013). PPARy signaling and metabolism: the good, the bad and the future. Nature Medicine, 19(5), 557-566. https://doi.org/10.1038/nm.3159

Al-Harthi, L. (2012). Wnt/B-catenin and its Diverse Physiological Cell Signaling Pathways in Neurodegenerative and Neuropsychiatric Disorders. Journal of Neuroimmune Pharmacology, 7(4), 725-730. https://doi.org/10.1007/s11481-012-9412-x

Ambacher, K. K., Pitzul, K. B., Karajgikar, M., Hamilton, A., Ferguson, S. S., and Cregan, S. P. (2012). The JNK- and AKT/GSK3 $\beta$ - Signaling Pathways Converge to Regulate Puma Induction and Neuronal Apoptosis Induced by Trophic Factor Deprivation. PLoS ONE, 7(10), e46885. https://doi.org/10.1371/journal.pone.0046885

Anea, C. B., Zhang, M., Stepp, D. W., Simkins, G. B., Reed, G., Fulton, D. J., and Rudic, R. D. (2009). Vascular disease in mice with a dysfunctional circadian clock. Circulation, 119(11), 1510-1517. https://doi.org/ 10.1161/CIRCULATIONAHA.108.827477

Angers, S., and Moon, R. T. (2009). Proximal events in Wnt signal transduction. Nature Reviews Molecular Cell Biology. https://doi.org/10.1038/ nrm2717

Barros, L. F. (2013). Metabolic signaling by lactate in the brain. Trends in Neurosciences, 36(7), 396-404. https://doi.org/10.1016/j.tins.2013.04.002

Bass, J., and Takahashi, J. S. (2010). Circadian integration of metabolism and energetics. Science (New York, N.Y.), 330(6009), 1349-1354. https:// doi.org/10.1126/science.1195027

Bauernfeind, A. L., Barks, S. K., Duka, T., Grossman, L. I., Hof, P. R., and Sherwood, C. C. (2014). Aerobic glycolysis in the primate brain: reconsidering the implications for growth and maintenance. Brain Structure and Function, 219(4), 1149-1167. https://doi.org/10.1007/ s00429-013-0662-z

Beaver, L. M., Klichko, V. I., Chow, E. S., KotwicaRolinska, J., Williamson, M., Orr, W. C., ... Giebultowicz, J. M. (2012). Circadian regulation of glutathione levels and biosynthesis in Drosophila melanogaster. PloS One, 7(11), e50454. https:// doi.org/10.1371/journal.pone.0050454

Behl, T., Kaur, I., Goel, H., and Kotwani, A. (2016). Implications of the endogenous PPAR-gamma ligand, 15-deoxy-delta-12, 14-prostaglandin J2, in diabetic retinopathy. Life Sciences, 153, 93-99. https://doi.org/10.1016/j.lfs.2016.03.054

Bélanger, M., Allaman, I., and Magistretti, P. J. (2011). Brain energy metabolism: focus on astrocyte-neuron metabolic cooperation. Cell Metabolism, 14(6), 724-738. https://doi.org/ 10.1016/j.cmet.2011.08.016

Benilova, I., Karran, E., and De Strooper, B. (2012). The toxic $A \beta$ oligomer and Alzheimer's disease: an emperor in need of clothes. Nature Neuroscience, 15(3), 349-357. https://doi.org/ 10.1038/nn.3028

Berwick, D. C., and Harvey, K. (2011). LRRK2 signaling pathways: the key to unlocking neurodegeneration? Trends in Cell Biology, 21(5), 257-265. https://doi.org/10.1016/j.tcb.2011.01.001

Berwick, D. C., and Harvey, K. (2012). The importance of Wnt signalling for neurodegeneration in Parkinson's disease. Biochemical Society Transactions, 40(5), 1123-1128. https:// doi.org/10.1042/BST20120122

Blesa, J., Trigo-Damas, I., Quiroga-Varela, A., and Jackson-Lewis, V. R. (2015). Oxidative stress and Parkinson's disease. Frontiers in Neuroanatomy, 9, 91. https://doi.org/10.3389/fnana.2015.00091 
Bonuccelli, U., Del Dotto, P., Lucetti, C., Petrozzi, L., Bernardini, S., Gambaccini, G., ... Piccini, P. (2000). Diurnal motor variations to repeated doses of levodopa in Parkinson's disease. Clinical Neuropharmacology, 23(1), 28-33.

Borghammer, P. (2012). Perfusion and metabolism imaging studies in Parkinson's disease. Danish Medical Journal, 59(6), B4466.

Borghammer, P., Chakravarty, M., Jonsdottir, K. Y., Sato, N., Matsuda, H., Ito, K., ... Gjedde, A. (2010). Cortical hypometabolism and hypoperfusion in Parkinson's disease is extensive: probably even at early disease stages. Brain Structure and Function, 214(4), 303-317. https://doi.org/10.1007/ s00429-010-0246-0

Braak, H., Ghebremedhin, E., Rüb, U., Bratzke, H., and Del Tredici, K. (2004). Stages in the development of Parkinson's disease-related pathology. Cell and Tissue Research, 318(1), 121-134. https://doi.org/10.1007/s00441-004-0956-9

Braissant, O., Foufelle, F., Scotto, C., Dauça, M., and Wahli, W. (1996). Differential expression of peroxisome proliferator-activated receptors (PPARs): tissue distribution of PPAR-alpha, -beta, and -gamma in the adult rat. Endocrinology, 137(1), 354-366. https://doi.org/10.1210/endo. 137.1.8536636

Bratic, A., and Larsson, N.-G. (2013). The role of mitochondria in aging. The Journal of Clinical Investigation, 123(3), 951-957. https://doi.org/ 10.1172/JCl64125

Breen, D. P., Vuono, R., Nawarathna, U., Fisher, K., Shneerson, J. M., Reddy, A. B., and Barker, R. A. (2014). Sleep and circadian rhythm regulation in early Parkinson disease. JAMA Neurology, 71(5), 589-595. https://doi.org/10.1001/jamaneurol. 2014.65

Bright, J. J., Kanakasabai, S., Chearwae, W., and Chakraborty, S. (2008). PPAR Regulation of Inflammatory Signaling in CNS Diseases. PPAR Research, 2008, 658520. https://doi.org/ $10.1155 / 2008 / 658520$

Cai, Y., Liu, S., Sothern, R. B., Xu, S., and Chan, P. (2010). Expression of clock genes Per1 and Bmal1 in total leukocytes in health and Parkinson's disease. European Journal of Neurology, 17(4), 550-554. https://doi.org/10.1111/ j.1468-1331.2009.02848.x

Calvo, J. R., González-Yanes, C., and Maldonado, M. D. (2013). The role of melatonin in the cells of the innate immunity: a review. Journal of Pineal Research, 55(2), 103-120. https://doi.org/10.1111/ jpi.12075

Cao, Y., Wang, H., Ouyang, Q., and Tu, Y. (2015). The free energy cost of accurate biochemical oscillations. Nature Physics, 11(9), 772-778. https://doi.org/10.1038/nphys3412

Cardinali, D. P., Pagano, E. S., Scacchi Bernasconi, P. A., Reynoso, R., and Scacchi, P. (2013). Melatonin and mitochondrial dysfunction in the central nervous system. Hormones and Behavior, 63(2), 322-330. https://doi.org/10.1016/j.yhbeh. 2012.02.020

Carta, A. R., Frau, L., Pisanu, A., Wardas, J., Spiga, S., and Carboni, E. (2011). Rosiglitazone decreases peroxisome proliferator receptor- $\gamma$ levels in microglia and inhibits TNF- $\alpha$ production: new evidences on neuroprotection in a progressive Parkinson's disease model. Neuroscience, 194, 250-261. https://doi.org/ 10.1016/j.neuroscience.2011.07.046

Chen, H., and Chan, D. C. (2009). Mitochondrial dynamics--fusion, fission, movement, and mitophagy--in neurodegenerative diseases. Human Molecular Genetics, 18(R2), R169-176. https://doi.org/10.1093/hmg/ddp326

Chen, L., and Yang, G. (2014). PPARs Integrate the Mammalian Clock and Energy Metabolism. PPAR Research, 2014, 653017. https://doi.org/ $10.1155 / 2014 / 653017$

Chen, T. L. (2004). Inhibition of growth and differentiation of osteoprogenitors in mouse bone marrow stromal cell cultures by increased donor age and glucocorticoid treatment. Bone, 35(1), 83-95. https://doi.org/10.1016/j.bone.2004.03.019

Chen, Y.-C., Wu, J.-S., Tsai, H.-D., Huang, C.-Y., Chen, J.-J., Sun, G. Y., and Lin, T.-N. (2012). Peroxisome proliferator-activated receptor gamma (PPAR- $y$ ) and neurodegenerative disorders. Molecular Neurobiology, 46(1), 114-124. https:// doi.org/10.1007/s12035-012-8259-8

Chiang, M.-C., Chen, C.-M., Lee, M.-R., Chen, H.W., Chen, H.-M., Wu, Y.-S., ... Chern, Y. (2010). Modulation of energy deficiency in Huntington's disease via activation of the peroxisome proliferator-activated receptor gamma. Human Molecular Genetics, 19(20), 4043-4058. https:// doi.org/10.1093/hmg/ddq322

Chiang, M.-C., Cheng, Y.-C., Nicol, C. J., Lin, K.-H., Yen, C.-H., Chen, S.-J., and Huang, R.-N. (2015). Rosiglitazone activation of PPARy-dependent signaling is neuroprotective in mutant huntingtin expressing cells. Experimental Cell Research, 338(2), 183-193. https://doi.org/10.1016/j.yexcr. 2015.09.005

Ciron, C., Lengacher, S., Dusonchet, J., Aebischer, P., and Schneider, B. L. (2012). Sustained expression of $P G C-1 \alpha$ in the rat nigrostriatal system selectively impairs dopaminergic function. 
Human Molecular Genetics, 21(8), 1861-1876. https://doi.org/10.1093/hmg/ddr618

Clark, I. E., Dodson, M. W., Jiang, C., Cao, J. H., Huh, J. R., Seol, J. H., ... Guo, M. (2006). Drosophila pink1 is required for mitochondrial function and interacts genetically with parkin. Nature, 441(7097), 1162-1166. https://doi.org/ 10.1038/nature04779

Clark, J., Reddy, S., Zheng, K., Betensky, R. A., and Simon, D. K. (2011). Association of PGC-1alpha polymorphisms with age of onset and risk of Parkinson's disease. BMC Medical Genetics, 12, 69. https://doi.org/10.1186/1471-2350-12-69

Clevers, H., and Nusse, R. (2012). Wnt/ $\beta$-catenin signaling and disease. Cell, 149(6), 1192-1205. https://doi.org/10.1016/j.cell.2012.05.012

Coppola, G., Marmolino, D., Lu, D., Wang, Q., Cnop, M., Rai, M., ... Geschwind, D. H. (2009). Functional genomic analysis of frataxin deficiency reveals tissue-specific alterations and identifies the PPARgamma pathway as a therapeutic target in Friedreich's ataxia. Human Molecular Genetics, 18(13), 2452-2461. https://doi.org/10.1093/hmg/ ddp183

Corona, J. C., and Duchen, M. R. (2015). PPARY and PGC-1 $\alpha$ as therapeutic targets in Parkinson's. Neurochemical Research, 40(2), 308-316. https:// doi.org/10.1007/s11064-014-1377-0

Crowley, S. J., and Eastman, C. I. (2013). Melatonin in the afternoons of a gradually advancing sleep schedule enhances the circadian rhythm phase advance. Psychopharmacology, 225(4), 825-837. https://doi.org/10.1007/s00213-012-2869-8

Csernus, V., and Mess, B. (2003). Biorhythms and pineal gland. Neuro Endocrinology Letters, 24(6), 404-411.

Czeisler, C. A., Dumont, M., Duffy, J. F., Steinberg, J. D., Richardson, G. S., Brown, E. N., ... Ronda, J. M. (1992). Association of sleep-wake habits in older people with changes in output of circadian pacemaker. Lancet (London, England), 340(8825), 933-936.

Devos, D., Kroumova, M., Bordet, R., Vodougnon, H., Guieu, J. D., Libersa, C., and Destee, A. (2003). Heart rate variability and Parkinson's disease severity. Journal of Neural Transmission (Vienna, Austria: 1996), 110(9), 997-1011. https:// doi.org/10.1007/s00702-003-0016-8

DiNuzzo, M., Maraviglia, B., and Giove, F. (2011). Why does the brain (not) have glycogen? BioEssays: News and Reviews in Molecular, Cellular and Developmental Biology, 33(5), 319-326. https://doi.org/10.1002/bies.201000151

Djouadi, F., Lecarpentier, Y., Hébert, J.-L., Charron, P., Bastin, J., and Coirault, C. (2009). A potential link between peroxisome proliferator-activated receptor signalling and the pathogenesis of arrhythmogenic right ventricular cardiomyopathy. Cardiovascular Research, 84(1), 83-90. https:// doi.org/10.1093/cvr/cvp183

Dubocovich, M. L. (2007). Melatonin receptors: role on sleep and circadian rhythm regulation. Sleep Medicine, 8 Suppl 3, 34-42. https://doi.org/ 10.1016/j.sleep.2007.10.007

Duffield, G. E., Best, J. D., Meurers, B. H., Bittner, A., Loros, J. J., and Dunlap, J. C. (2002). Circadian programs of transcriptional activation, signaling, and protein turnover revealed by microarray analysis of mammalian cells. Current Biology: CB, 12(7), 551-557.

Duffy, J. F., Zeitzer, J. M., Rimmer, D. W., Klerman, E. B., Dijk, D.-J., and Czeisler, C. A. (2002). Peak of circadian melatonin rhythm occurs later within the sleep of older subjects. American Journal of Physiology. Endocrinology and Metabolism, 282(2), E297-303. https://doi.org/10.1152/ ajpendo.00268.2001

Dun, Y., Li, G., Yang, Y., Xiong, Z., Feng, M., Wang, M., ... Ma, R. (2012). Inhibition of the canonical Wnt pathway by Dickkopf-1 contributes to the neurodegeneration in 6-OHDA-lesioned rats. Neuroscience Letters, 525(2), 83-88. https:// doi.org/10.1016/j.neulet.2012.07.030

Dunn, L., Allen, G. F., Mamais, A., Ling, H., Li, A., Duberley, K. E., ... Bandopadhyay, R. (2014). Dysregulation of glucose metabolism is an early event in sporadic Parkinson's disease. Neurobiology of Aging, 35(5), 1111-1115. https:// doi.org/10.1016/j.neurobiolaging.2013.11.001

Edison, P., Ahmed, I., Fan, Z., Hinz, R., Gelosa, G., Ray Chaudhuri, K., ... Brooks, D. J. (2013). Microglia, amyloid, and glucose metabolism in Parkinson's disease with and without dementia. Neuropsychopharmacology: Official Publication of the American College of Neuropsychopharmacology, 38(6), 938-949. https://doi.org/10.1038/ npp.2012.255

Elbrecht, A., Chen, Y., Cullinan, C. A., Hayes, N., Leibowitz, M. d, Moller, D. E., and Berger, J. (1996). Molecular cloning, expression and characterization of human peroxisome proliferator activated receptors gamma 1 and gamma 2 . Biochemical and Biophysical Research Communications, 224(2), 431-437.

Esmaeili, M. A., Yadav, S., Gupta, R. K., Waggoner, G. R., Deloach, A., Calingasan, N. Y., ... Kiaei, M. (2016). Preferential PPAR- $\alpha$ activation reduces neuroinflammation, and blocks neurodegeneration in vivo. Human Molecular Genetics, 25(2), 317-327. https://doi.org/10.1093/hmg/ddv477 
Evans, J. A., and Davidson, A. J. (2013). Health consequences of circadian disruption in humans and animal models. Progress in Molecular Biology and Translational Science, 119, 283-323. https:// doi.org/10.1016/B978-0-12-396971-2.00010-5

Fajas, L., Auboeuf, D., Raspé, E., Schoonjans, K., Lefebvre, A. M., Saladin, R., ... Auwerx, J. (1997). The organization, promoter analysis, and expression of the human PPARgamma gene. The Journal of Biological Chemistry, 272(30), 18779-18789.

Farshbaf, M. J., Ghaedi, K., Shirani, M., and NasrEsfahani, M. H. (2014). Peroxisome proliferator activated receptor gamma (PPARy) as a therapeutic target for improvement of cognitive performance in Fragile-X. Medical Hypotheses, 82(3), 291-294. https://doi.org/10.1016/j.mehy. 2013.12.012

Fontaine, C., Dubois, G., Duguay, Y., Helledie, T., Vu-Dac, N., Gervois, P., ... Staels, B. (2003). The orphan nuclear receptor Rev-Erbalpha is a peroxisome proliferator-activated receptor (PPAR) gamma target gene and promotes PPARgammainduced adipocyte differentiation. The Journal of Biological Chemistry, 278(39), 37672-37680. https://doi.org/10.1074/jbc.M304664200

Franco-lborra, S., Vila, M., and Perier, C. (2016). The Parkinson Disease Mitochondrial Hypothesis: Where Are We at? The Neuroscientist: A Review Journal Bringing Neurobiology, Neurology and Psychiatry, 22(3), 266-277. https://doi.org/ $10.1177 / 1073858415574600$

Galano, A., Tan, D. X., and Reiter, R. J. (2013). On the free radical scavenging activities of melatonin's metabolites, AFMK and AMK. Journal of Pineal Research, 54(3), 245-257. https:// doi.org/10.1111/jpi.12010

Galea, E., Heneka, M. T., Dello Russo, C., and Feinstein, D. L. (2003). Intrinsic regulation of brain inflammatory responses. Cellular and Molecular Neurobiology, 23(4-5), 625-635.

Gao, J., Huang, X., Park, Y., Hollenbeck, A., Blair, A., Schatzkin, A., and Chen, H. (2011). Daytime napping, nighttime sleeping, and Parkinson disease. American Journal of Epidemiology, 173(9), 1032-1038. https://doi.org/10.1093/aje/ kwq478

García-Bueno, B., Caso, J. R., Pérez-Nievas, B. G., Lorenzo, P., and Leza, J. C. (2007). Effects of peroxisome proliferator-activated receptor gamma agonists on brain glucose and glutamate transporters after stress in rats. Neuropsychopharmacology: Official Publication of the American College of Neuropsychopharmacology, 32(6), 1251-1260. https://doi.org/10.1038/sj.npp.1301252
García-Bueno, B., Madrigal, J. L. M., Lizasoain, I., Moro, M. A., Lorenzo, P., and Leza, J. C. (2005). The anti-inflammatory prostaglandin 15d-PGJ2 decreases oxidative/nitrosative mediators in brain after acute stress in rats. Psychopharmacology, 180(3), 513-522. https://doi.org/10.1007/ s00213-005-2195-5

Garcia-Gras, E., Lombardi, R., Giocondo, M. J., Willerson, J. T., Schneider, M. D., Khoury, D. S., and Marian, A. J. (2006). Suppression of canonical $\mathrm{Wnt} /$ beta-catenin signaling by nuclear plakoglobin recapitulates phenotype of arrhythmogenic right ventricular cardiomyopathy. The Journal of Clinical Investigation, 116(7), 2012-2021. https://doi.org/10.1172/JCl27751

Gekakis, N., Staknis, D., Nguyen, H. B., Davis, F. C., Wilsbacher, L. D., King, D. P., ... Weitz, C. J. (1998). Role of the CLOCK protein in the mammalian circadian mechanism. Science (New York, N.Y.), 280(5369), 1564-1569.

Ghosh, S., Patel, N., Rahn, D., McAllister, J., Sadeghi, S., Horwitz, G., ... Swerdlow, R. H. (2007). The thiazolidinedione pioglitazone alters mitochondrial function in human neuron-like cells. Molecular Pharmacology, 71(6), 1695-1702. https://doi.org/10.1124/mol.106.033845

Giese, K. P. (2009). GSK-3: a key player in neurodegeneration and memory. IUBMB Life, 61(5), 516-521. https://doi.org/10.1002/iub.187

Godin, J. D., Poizat, G., Hickey, M. A., Maschat, F., and Humbert, S. (2010). Mutant huntingtinimpaired degradation of beta-catenin causes neurotoxicity in Huntington's disease. The EMBO Journal, 29(14), 2433-2445. https://doi.org/ 10.1038/emboj.2010.117

Goldbeter, A. (2002). Computational approaches to cellular rhythms. Nature, 420(6912), 238-245. https://doi.org/10.1038/nature01259

Goldbeter, A. (2017). Dissipative structures and biological rhythms. Chaos (Woodbury, N.Y.), 27(10), 104612. https://doi.org/10.1063/1.4990783

Goldbeter, A., and Pourquié, O. (2008). Modeling the segmentation clock as a network of coupled oscillations in the Notch, Wnt and FGF signaling pathways. Journal of Theoretical Biology, 252(3), 574-585. https://doi.org/10.1016/j.jtbi.2008.01.006

Goodwin, B. C. (1965). Oscillatory behavior in enzymatic control processes. Advances in Enzyme Regulation, 3, 425-438.

Grandemange, S., Herzig, S., and Martinou, J.-C. (2009). Mitochondrial dynamics and cancer. Seminars in Cancer Biology, 19(1), 50-56. https:// doi.org/10.1016/j.semcancer.2008.12.001

Gravotta, L., Gavrila, A. M., Hood, S., and Amir, S. (2011). Global depletion of dopamine using 
intracerebroventricular 6-hydroxydopamine injection disrupts normal circadian wheel-running patterns and PERIOD2 expression in the rat forebrain. Journal of Molecular Neuroscience: MN, 45(2), 162-171. https://doi.org/10.1007/ s12031-011-9520-8

Green, C. B., Douris, N., Kojima, S., Strayer, C. A., Fogerty, J., Lourim, D., ... Besharse, J. C. (2007). Loss of Nocturnin, a circadian deadenylase, confers resistance to hepatic steatosis and dietinduced obesity. Proceedings of the National Academy of Sciences of the United States of America, 104(23), 9888-9893. https://doi.org/ 10.1073/pnas.0702448104

Grinberg, L. T., Rueb, U., Alho, A. T. di L., and Heinsen, H. (2010). Brainstem pathology and non-motor symptoms in PD. Journal of the Neurological Sciences, 289(1-2), 81-88. https:// doi.org/10.1016/j.jns.2009.08.021

Grygiel-Górniak, B. (2014). Peroxisome proliferatoractivated receptors and their ligands: nutritional and clinical implications--a review. Nutrition Journal, 13, 17. https://doi.org/10.1186/1475-2891-13-17

Guo, B., Chatterjee, S., Li, L., Kim, J. M., Lee, J., Yechoor, V. K., ... Ma, K. (2012). The clock gene, brain and muscle Arnt-like 1, regulates adipogenesis via Wnt signaling pathway. FASEB Journal: Official Publication of the Federation of American Societies for Experimental Biology, 26(8), 3453-3463. https://doi.org/10.1096/fj. 12-205781

Guven, C., Taskin, E., and Akcakaya, H. (2016). Melatonin Prevents Mitochondrial Damage Induced by Doxorubicin in Mouse Fibroblasts Through Ampk-Ppar Gamma-Dependent Mechanisms. Medical Science Monitor: International Medical Journal of Experimental and Clinical Research, 22, 438-446.

Häbig, K., Walter, M., Poths, S., Riess, O., and Bonin, M. (2008). RNA interference of LRRK2microarray expression analysis of a Parkinson's disease key player. Neurogenetics, 9(2), 83-94. https://doi.org/10.1007/s10048-007-0114-0

Haramizu, S., Ota, N., Hase, T., and Murase, T. (2011). Aging-associated changes in physical performance and energy metabolism in the senescence-accelerated mouse. The Journals of Gerontology. Series A, Biological Sciences and Medical Sciences, 66(6), 646-655. https://doi.org/ 10.1093/gerona/glr037

Hardin, P. E., Hall, J. C., and Rosbash, M. (1990). Feedback of the Drosophila period gene product on circadian cycling of its messenger RNA levels. Nature, 343(6258), 536-540. https://doi.org/ $10.1038 / 343536 \mathrm{a} 0$
Harris, R. A., Tindale, L., and Cumming, R. C. (2014). Age-dependent metabolic dysregulation in cancer and Alzheimer's disease. Biogerontology, 15(6), 559-577. https://doi.org/10.1007/ s10522-014-9534-z

Harrison-Uy, S. J., and Pleasure, S. J. (2012). Wnt signaling and forebrain development. Cold Spring Harbor Perspectives in Biology, 4(7), a008094. https://doi.org/10.1101/cshperspect.a008094

He, T. C., Sparks, A. B., Rago, C., Hermeking, H., Zawel, L., da Costa, L. T., ... Kinzler, K. W. (1998). Identification of c-MYC as a target of the APC pathway. Science (New York, N.Y.), 281(5382), 1509-1512.

Heras-Sandoval, D., Pérez-Rojas, J. M., Hernández-Damián, J., and Pedraza-Chaverri, J. (2014). The role of PI3K/AKT/mTOR pathway in the modulation of autophagy and the clearance of protein aggregates in neurodegeneration. Cellular Signalling, 26(12), 2694-2701. https://doi.org/ 10.1016/j.cellsig.2014.08.019

Hirsch, E. C., Vyas, S., and Hunot, S. (2012). Neuroinflammation in Parkinson's disease. Parkinsonism and Related Disorders, 18 Suppl 1, S210-212. https:// doi.org/10.1016/S1353-8020(11)70065-7

Hoepken, H.-H., Gispert, S., Morales, B., Wingerter, O., Del Turco, D., Mülsch, A., ... Auburger, G. (2007). Mitochondrial dysfunction, peroxidation damage and changes in glutathione metabolism in PARK6. Neurobiology of Disease, 25(2), 401-411. https://doi.org/10.1016/j.nbd. 2006.10.007

Hofman, M. A. (2000). The human circadian clock and aging. Chronobiology International, 17(3), 245-259.

Hogenesch, J. B., Gu, Y. Z., Jain, S., and Bradfield, C. A. (1998). The basic-helix-loop-helix-PAS orphan MOP3 forms transcriptionally active complexes with circadian and hypoxia factors. Proceedings of the National Academy of Sciences of the United States of America, 95(10), 5474-5479.

Hood, S., Cassidy, P., Cossette, M.-P., Weigl, Y., Verwey, M., Robinson, B., ... Amir, S. (2010). Endogenous dopamine regulates the rhythm of expression of the clock protein PER2 in the rat dorsal striatum via daily activation of D2 dopamine receptors. The Journal of Neuroscience: The Official Journal of the Society for Neuroscience, 30(42), 14046-14058. https:// doi.org/10.1523/JNEUROSCI.2128-10.2010

Hoppe, J. B., Frozza, R. L., Horn, A. P., Comiran, R. A., Bernardi, A., Campos, M. M., ... Salbego, C. (2010). Amyloid-beta neurotoxicity in organotypic culture is attenuated by melatonin: involvement of 
GSK-3beta, tau and neuroinflammation. Journal of Pineal Research, 48(3), 230-238. https:// doi.org/10.1111/j.1600-079X.2010.00747.x

Hur, E.-M., and Zhou, F.-Q. (2010). GSK3 signalling in neural development. Nature Reviews. Neuroscience, 11(8), 539-551. https://doi.org/ $10.1038 / n r n 2870$

Ille, F., and Sommer, L. (2005). Wnt signaling: multiple functions in neural development. Cellular and Molecular Life Sciences: CMLS, 62(10), 1100-1108. https://doi.org/10.1007/s00018-005-4552-2

Imbesi, M., Yildiz, S., Dirim Arslan, A., Sharma, R., Manev, H., and Uz, T. (2009). Dopamine receptormediated regulation of neuronal "clock" gene expression. Neuroscience, 158(2), 537-544. https://doi.org/10.1016/j.neuroscience. 2008.10.044

Inestrosa, N. C., and Arenas, E. (2010). Emerging roles of Wnts in the adult nervous system. Nature Reviews. Neuroscience, 11(2), 77-86. https:// doi.org/10.1038/nrn2755

Inestrosa, N. C., Montecinos-Oliva, C., and Fuenzalida, M. (2012). Wnt signaling: role in Alzheimer disease and schizophrenia. Journal of Neuroimmune Pharmacology: The Official Journal of the Society on Neurolmmune Pharmacology, 7(4), 788-807. https://doi.org/10.1007/s11481-012-9417-5

Islam, M. T. (2017). Oxidative stress and mitochondrial dysfunction-linked neurodegenerative disorders. Neurological Research, 39(1), 73-82. https://doi.org/ 10.1080/01616412.2016.1251711

Janich, P., Pascual, G., Merlos-Suárez, A., Batlle, E., Ripperger, J., Albrecht, U., ... Benitah, S. A. (2011). The circadian molecular clock creates epidermal stem cell heterogeneity. Nature, 480(7376), 209-214. https://doi.org/10.1038/ nature10649

Kapadia, R., Yi, J.-H., and Vemuganti, R. (2008). Mechanisms of anti-inflammatory and neuroprotective actions of PPAR-gamma agonists. Frontiers in Bioscience: A Journal and Virtual Library, 13, 1813-1826.

Kato, H., Tanaka, G., Masuda, S., Ogasawara, J., Sakurai, T., Kizaki, T., ... Izawa, T. (2015). Melatonin promotes adipogenesis and mitochondrial biogenesis in 3T3-L1 preadipocytes. Journal of Pineal Research, 59(2), 267-275. https://doi.org/ 10.1111/jpi.12259

Kawano, Y., and Kypta, R. (2003). Secreted antagonists of the Wnt signalling pathway. Journal of Cell Science, 116(Pt 13), 2627-2634. https:// doi.org/10.1242/jcs.00623

Kim, G. H., Kim, J. E., Rhie, S. J., and Yoon, S. (2015). The Role of Oxidative Stress in Neurodegenerative Diseases. Experimental
Neurobiology, 24(4), 325-340. https://doi.org/ 10.5607/en.2015.24.4.325

Ko, C. H., and Takahashi, J. S. (2006). Molecular components of the mammalian circadian clock. Human Molecular Genetics, 15 Spec No 2, R271-277. https://doi.org/10.1093/hmg/ddI207

Kondepudi, D., and Prigogine, I. (1999). Modern thermodynamics from heat engines to dissipative structures. New-York: Willey and Sons.

Kondratova, A. A., and Kondratov, R. V. (2012). The circadian clock and pathology of the ageing brain. Nature Reviews. Neuroscience, 13(5), 325-335. https://doi.org/10.1038/nrn3208

Korvala, J., Jüppner, H., Mäkitie, O., Sochett, E., Schnabel, D., Mora, S., ... Männikkö, M. (2012). Mutations in LRP5 cause primary osteoporosis without features of $\mathrm{OI}$ by reducing Wnt signaling activity. BMC Medical Genetics, 13, 26. https:// doi.org/10.1186/1471-2350-13-26

Krishnan, N., Davis, A. J., and Giebultowicz, J. M. (2008). Circadian regulation of response to oxidative stress in Drosophila melanogaster. Biochemical and Biophysical Research Communications, 374(2), 299-303. https://doi.org/ 10.1016/j.bbrc.2008.07.011

Krishnan, N., Kretzschmar, D., Rakshit, K., Chow, E., and Giebultowicz, J. M. (2009). The circadian clock gene period extends healthspan in aging Drosophila melanogaster. Aging, 1(11), 937-948. https://doi.org/10.18632/aging.100103

Lauretti, E., Di Meco, A., Merali, S., and Praticò, D. (2017). Circadian rhythm dysfunction: a novel environmental risk factor for Parkinson's disease. Molecular Psychiatry, 22(2), 280-286. https:// doi.org/10.1038/mp.2016.47

Lecarpentier, Y., Krokidis, X., Martin, P., Pineau, T., Hébert, J.-L., Quillard, J., ... Coirault, C. (2008). Increased entropy production in diaphragm muscle of PPAR alpha knockout mice. Journal of Theoretical Biology, 250(1), 92-102. https:// doi.org/10.1016/j.jtbi.2007.09.022

Lecarpentier, Yves, Claes, V., Duthoit, G., and Hébert, J.-L. (2014). Circadian rhythms, Wnt/betacatenin pathway and PPAR alpha/gamma profiles in diseases with primary or secondary cardiac dysfunction. Frontiers in Physiology, 5, 429. https://doi.org/10.3389/fphys.2014.00429

Lecarpentier, Yves, Claes, V., and Hébert, J.-L. (2010). PPARs, Cardiovascular Metabolism, and Function: Near- or Far-from-Equilibrium Pathways. PPAR Research, 2010. https://doi.org/ 10.1155/2010/783273

Lecarpentier, Yves, Claes, V., Vallée, A., and Hébert, J.-L. (2017a). Interactions between PPAR Gamma and the Canonical Wnt/Beta-Catenin 
Pathway in Type 2 Diabetes and Colon Cancer. PPAR Research, 2017, 1-9. https://doi.org/ $10.1155 / 2017 / 5879090$

Lecarpentier, Yves, Claes, V., Vallée, A., and Hébert, J.-L. (2017b). Thermodynamics in cancers: opposing interactions between PPAR gamma and the canonical WNT/beta-catenin pathway. Clinical and Translational Medicine, 6(1), 14. https://doi.org/10.1186/s40169-017-0144-7

Lecarpentier, Yves, and Vallée, A. (2016). Opposite Interplay between PPAR Gamma and Canonical Wnt/Beta-Catenin Pathway in Amyotrophic Lateral Sclerosis. Frontiers in Neurology, 7, 100. https:// doi.org/10.3389/fneur.2016.00100

L'episcopo, F., Serapide, M. F., Tirolo, C., Testa, N., Caniglia, S., Morale, M. C., ... Marchetti, B. (2011). A Wnt1 regulated Frizzled-1/ $\beta-C a t e n i n$ signaling pathway as a candidate regulatory circuit controlling mesencephalic dopaminergic neuron-astrocyte crosstalk: Therapeutical relevance for neuron survival and neuroprotection. Molecular Neurodegeneration, 6, 49. https://doi.org/10.1186/1750-1326-6-49

L'Episcopo, F., Tirolo, C., Testa, N., Caniglia, S., Morale, M. C., Deleidi, M., ... Marchetti, B. (2012). Plasticity of subventricular zone neuroprogenitors in MPTP (1-methyl-4-phenyl-1,2,3,6-tetrahydropyridine) mouse model of Parkinson's disease involves cross talk between inflammatory and Wnt/ $\beta$-catenin signaling pathways: functional consequences for neuroprotection and repair. The Journal of Neuroscience: The Official Journal of the Society for Neuroscience, 32(6), 2062-2085. https://doi.org/10.1523/JNEUROSCI.5259-11.2012

Libro, R., Bramanti, P., and Mazzon, E. (2016). The role of the Wnt canonical signaling in neurodegenerative diseases. Life Sciences, 158, 78-88. https://doi.org/10.1016/j.Ifs.2016.06.024

Lin, F., Chen, Y., Li, X., Zhao, Q., and Tan, Z. (2013). Over-expression of circadian clock gene Bmal1 affects proliferation and the canonical Wnt pathway in NIH-3T3 cells. Cell Biochemistry and Function, 31(2), 166-172. https://doi.org/10.1002/ cbf.2871

Liu, J., Wang, H., Zuo, Y., and Farmer, S. R. (2006). Functional interaction between peroxisome proliferator-activated receptor gamma and betacatenin. Molecular and Cellular Biology, 26(15), 5827-5837. https://doi.org/10.1128/MCB.00441-06

Lu, D., and Carson, D. A. (2010). Repression of beta-catenin signaling by PPAR gamma ligands. European Journal of Pharmacology, 636(1-3), 198-202. https://doi.org/10.1016/j.ejphar. 2010.03.010
Luque-Contreras, D., Carvajal, K., Toral-Rios, D., Franco-Bocanegra, D., and Campos-Peña, V. (2014). Oxidative stress and metabolic syndrome: cause or consequence of Alzheimer's disease? Oxidative Medicine and Cellular Longevity, 2014, 497802. https://doi.org/10.1155/2014/497802

MacDonald, B. T., Tamai, K., and He, X. (2009). Wnt/beta-catenin signaling: components, mechanisms, and diseases. Developmental Cell, 17(1), 9-26. https://doi.org/10.1016/j.devcel. 2009.06.016

Maguire-Zeiss, K. A., and Federoff, H. J. (2010). Future directions for immune modulation in neurodegenerative disorders: focus on Parkinson's disease. Journal of Neural Transmission (Vienna, Austria: 1996), 117(8), 1019-1025. https://doi.org/ 10.1007/s00702-010-0431-6

Marchetti, B., and Pluchino, S. (2013). Wnt your brain be inflamed? Yes, it Wnt! Trends in Molecular Medicine, 19(3), 144-156. https:// doi.org/10.1016/j.molmed.2012.12.001

Marpegan, L., Swanstrom, A. E., Chung, K., Simon, T., Haydon, P. G., Khan, S. K., ... Beaulé, C. (2011). Circadian regulation of ATP release in astrocytes. The Journal of Neuroscience: The Official Journal of the Society for Neuroscience, 31(23), 8342-8350. https://doi.org/10.1523/ JNEUROSCI.6537-10.2011

Mattam, U., and Jagota, A. (2015). Daily rhythms of serotonin metabolism and the expression of clock genes in suprachiasmatic nucleus of rotenoneinduced Parkinson's disease male Wistar rat model and effect of melatonin administration. Biogerontology, 16(1), 109-123. https://doi.org/ 10.1007/s10522-014-9541-0

Mauriz, J. L., Collado, P. S., Veneroso, C., Reiter, R. J., and González-Gallego, J. (2013). A review of the molecular aspects of melatonin's anti-inflammatory actions: recent insights and new perspectives. Journal of Pineal Research, 54(1), 1-14. https:// doi.org/10.1111/j.1600-079X.2012.01014.X

Mizobuchi, M., Hineno, T., Kakimoto, Y., and Hiratani, K. (1993). Increase of plasma adrenocorticotrophin and cortisol in 1-methyl-4phenyl-1,2,3,6-tetrahydropyridine (MPTP)-treated dogs. Brain Research, 612(1-2), 319-321.

Moldes, M., Zuo, Y., Morrison, R. F., Silva, D., Park, B.-H., Liu, J., and Farmer, S. R. (2003). Peroxisome-proliferator-activated receptor gamma suppresses Wnt/beta-catenin signalling during adipogenesis. The Biochemical Journal, 376(Pt 3), 607-613. https://doi.org/10.1042/ BJ20030426

Mosconi, L., Pupi, A., and De Leon, M. J. (2008). Brain glucose hypometabolism and oxidative 
stress in preclinical Alzheimer's disease. Annals of the New York Academy of Sciences, 1147, 180-195. https://doi.org/10.1196/annals.1427.007

Musiek, E. S. (2015). Circadian clock disruption in neurodegenerative diseases: cause and effect? Frontiers in Pharmacology, 6, 29. https://doi.org/ 10.3389/fphar.2015.00029

Niida, A., Hiroko, T., Kasai, M., Furukawa, Y., Nakamura, Y., Suzuki, Y., ... Akiyama, T. (2004). DKK1, a negative regulator of Wnt signaling, is a target of the beta-catenin/TCF pathway. Oncogene, 23(52), 8520-8526. https://doi.org/ 10.1038/sj.onc.1207892

Obel, L. F., Müller, M. S., Walls, A. B., Sickmann, H. M., Bak, L. K., Waagepetersen, H. S., and Schousboe, A. (2012). Brain glycogen-new perspectives on its metabolic function and regulation at the subcellular level. Frontiers in Neuroenergetics, 4, 3. https://doi.org/10.3389/ fnene.2012.00003

Oliva, C. A., Vargas, J. Y., and Inestrosa, N. C. (2013). Wnts in adult brain: from synaptic plasticity to cognitive deficiencies. Frontiers in Cellular Neuroscience, 7, 224. https://doi.org/ 10.3389/fncel.2013.00224

Orellana, A. M. M., Vasconcelos, A. R., Leite, J. A., de Sá Lima, L., Andreotti, D. Z., Munhoz, C. D., ... Scavone, C. (2015). Age-related neuroinflammation and changes in AKT-GSK-3 $\beta$ and WNT/ $\beta$-CATENIN signaling in rat hippocampus. Aging, 7(12), 1094-1111. https://doi.org/10.18632/ aging. 100853

Oz, G., Seaquist, E. R., Kumar, A., Criego, A. B., Benedict, L. E., Rao, J. P., ... Gruetter, R. (2007). Human brain glycogen content and metabolism: implications on its role in brain energy metabolism. American Journal of Physiology. Endocrinology and Metabolism, 292(3), E946-951. https://doi.org/10.1152/ajpendo. 00424.2006

Palacino, J. J., Sagi, D., Goldberg, M. S., Krauss, S., Motz, C., Wacker, M., ... Shen, J. (2004). Mitochondrial dysfunction and oxidative damage in parkin-deficient mice. The Journal of Biological Chemistry, 279(18), 18614-18622. https://doi.org/ 10.1074/jbc.M401135200

Panaccione, I., Napoletano, F., Forte, A. M., Kotzalidis, G. D., Del Casale, A., Rapinesi, C., ... Sani, G. (2013). Neurodevelopment in schizophrenia: the role of the wnt pathways. Current Neuropharmacology, 11(5), 535-558. https://doi.org/10.2174/1570159X113119990037

Parekh, P. K., Ozburn, A. R., and McClung, C. A. (2015). Circadian clock genes: effects on dopamine, reward and addiction. Alcohol
(Fayetteville, N.Y.), 49(4), 341-349. https://doi.org/ 10.1016/j.alcohol.2014.09.034

Parish, C. L., Castelo-Branco, G., Rawal, N., Tonnesen, J., Sorensen, A. T., Salto, C., ... Arenas, E. (2008). Wnt5a-treated midbrain neural stem cells improve dopamine cell replacement therapy in parkinsonian mice. The Journal of Clinical Investigation, 118(1), 149-160. https:// doi.org/10.1172/JCI32273

Park, K. S., Lee, R. D., Kang, S.-K., Han, S. Y., Park, K. L., Yang, K. H., ... Hong, J. T. (2004). Neuronal differentiation of embryonic midbrain cells by upregulation of peroxisome proliferatoractivated receptor-gamma via the JNK-dependent pathway. Experimental Cell Research, 297(2), 424-433. https://doi.org/10.1016/j.yexcr. 2004.03.034

Patel, A. B., Lai, J. C. K., Chowdhury, G. M. I., Hyder, F., Rothman, D. L., Shulman, R. G., and Behar, K. L. (2014). Direct evidence for activitydependent glucose phosphorylation in neurons with implications for the astrocyte-to-neuron lactate shuttle. Proceedings of the National Academy of Sciences of the United States of America, 111(14), 5385-5390. https://doi.org/ 10.1073/pnas.1403576111

Pesah, Y., Pham, T., Burgess, H., Middlebrooks, B., Verstreken, P., Zhou, Y., ... Mardon, G. (2004). Drosophila parkin mutants have decreased mass and cell size and increased sensitivity to oxygen radical stress. Development (Cambridge, England), 131(9), 2183-2194. https://doi.org/ 10.1242/dev.01095

Pevet, P., and Challet, E. (2011). Melatonin: both master clock output and internal time-giver in the circadian clocks network. Journal of Physiology, Paris, 105(4-6), 170-182. https://doi.org/10.1016/ j.jphysparis.2011.07.001

Piccini, P., Del Dotto, P., Pardini, C., D'Antonio, P., Rossi, G., and Bonuccelli, U. (1991). [Diurnal worsening in Parkinson patients treated with levodopa]. Rivista Di Neurologia, 61(6), 219-224.

Pinto, M., Nissanka, N., Peralta, S., Brambilla, R., Diaz, F., and Moraes, C. T. (2016). Pioglitazone ameliorates the phenotype of a novel Parkinson's disease mouse model by reducing neuroinflammation. Molecular Neurodegeneration, 11, 25. https://doi.org/10.1186/s13024-016-0090-7

Prigogine, I. (1986). Life and physics. New perspectives. Cell Biophysics, 9(1-2), 217-224. https://doi.org/10.1007/BF02797383

Prigogine, I., Nicolis, G., and Babloyantz, A. (1974). Nonequilibrium problems in biological phenomena. Annals of the New York Academy of Sciences, 231(1), 99-105. 
Rawal, N., Corti, O., Sacchetti, P., Ardilla-Osorio, H., Sehat, B., Brice, A., and Arenas, E. (2009). Parkin protects dopaminergic neurons from excessive Wnt/beta-catenin signaling. Biochemical and Biophysical Research Communications, 388(3), 473-478. https://doi.org/10.1016/j.bbrc.2009.07.014

Reppert, S. M., and Weaver, D. R. (2002). Coordination of circadian timing in mammals. Nature, 418(6901), 935-941. https://doi.org/ 10.1038/nature00965

Ricote, M., and Glass, C. K. (2007). PPARs and molecular mechanisms of transrepression. Biochimica Et Biophysica Acta, 1771(8), 926-935. https://doi.org/10.1016/j.bbalip.2007.02.013

Riggs, J. E. (1998). Aging, increasing genomic entropy, and neurodegenerative disease. Neurologic Clinics, 16(3), 757-770.

Rong, J. X., Klein, J.-L. D., Qiu, Y., Xie, M., Johnson, J. H., Waters, K. M., ... Strum, J. C. (2011). Rosiglitazone Induces Mitochondrial Biogenesis in Differentiated Murine 3T3-L1 and C3H/10T1/2 Adipocytes. PPAR Research, 2011, 179454. https://doi.org/10.1155/2011/179454

Rosales-Corral, S. A., Acuña-Castroviejo, D., CotoMontes, A., Boga, J. A., Manchester, L. C., Fuentes-Broto, L., ... Reiter, R. J. (2012). Alzheimer's disease: pathological mechanisms and the beneficial role of melatonin. Journal of Pineal Research, 52(2), 167-202. https://doi.org/ 10.1111/j.1600-079X.2011.00937.x

Rosi, M. C., Luccarini, I., Grossi, C., Fiorentini, A., Spillantini, M. G., Prisco, A., ... Casamenti, F. (2010). Increased Dickkopf-1 expression in transgenic mouse models of neurodegenerative disease. Journal of Neurochemistry, 112(6), 1539-1551. https://doi.org/ 10.1111/j.1471-4159.2009.06566.x

Sahar, S., and Sassone-Corsi, P. (2009). Metabolism and cancer: the circadian clock connection. Nature Reviews. Cancer, 9(12), 886-896. https://doi.org/10.1038/nrc2747

Salinas, P. C. (2012). Wnt signaling in the vertebrate central nervous system: from axon guidance to synaptic function. Cold Spring Harbor Perspectives in Biology, 4(2). https://doi.org/ 10.1101/cshperspect.a008003

Sancar, A., Lindsey-Boltz, L. A., Unsal-Kaçmaz, K., and Linn, S. (2004). Molecular mechanisms of mammalian DNA repair and the DNA damage checkpoints. Annual Review of Biochemistry, 73, 39-85. https://doi.org/10.1146/annurev.biochem. 73.011303.073723

Sandler, S. (2006). Chemical and Engineering Thermodynamics (4th ed.). New-York: Wiely.

Schapira, A. H. V. (2008). Mitochondria in the aetiology and pathogenesis of Parkinson's disease. The Lancet. Neurology, 7(1), 97-109. https://doi.org/10.1016/S1474-4422(07)70327-7

Schibler, U., and Sassone-Corsi, P. (2002). A web of circadian pacemakers. Cell, 111(7), 919-922.

Schild, R. L., Schaiff, W. T., Carlson, M. G., Cronbach, E. J., Nelson, D. M., and Sadovsky, Y. (2002). The activity of PPAR gamma in primary human trophoblasts is enhanced by oxidized lipids. The Journal of Clinical Endocrinology and Metabolism, 87(3), 1105-1110. https://doi.org/ 10.1210/jcem.87.3.8284

Schurr, A. (2014). Cerebral glycolysis: a century of persistent misunderstanding and misconception. Frontiers in Neuroscience, 8, 360. https://doi.org/ 10.3389/fnins.2014.00360

Semënov, M. V., Zhang, X., and He, X. (2008). DKK1 antagonizes Wnt signaling without promotion of LRP6 internalization and degradation. The Journal of Biological Chemistry, 283(31), 21427-21432. https://doi.org/10.1074/ jbc.M800014200

Semenza, G. L. (2010). HIF-1: upstream and downstream of cancer metabolism. Current Opinion in Genetics and Development, 20(1), 51-56. https://doi.org/10.1016/j.gde.2009.10.009

Sharma, C., Pradeep, A., Wong, L., Rana, A., and Rana, B. (2004). Peroxisome proliferatoractivated receptor gamma activation can regulate beta-catenin levels via a proteasome-mediated and adenomatous polyposis coli-independent pathway. The Journal of Biological Chemistry, 279(34), 35583-35594. https://doi.org/10.1074/ jbc.M403143200

Shtutman, M., Zhurinsky, J., Simcha, I., Albanese, C., D'Amico, M., Pestell, R., and Ben-Ze'ev, A. (1999). The cyclin D1 gene is a target of the betacatenin/LEF-1 pathway. Proceedings of the National Academy of Sciences of the United States of America, 96(10), 5522-5527.

Siersbæk, M. S., Loft, A., Aagaard, M. M., Nielsen, R., Schmidt, S. F., Petrovic, N., ... Mandrup, S. (2012). Genome-wide profiling of peroxisome proliferator-activated receptor $\mathrm{Y}$ in primary epididymal, inguinal, and brown adipocytes reveals depot-selective binding correlated with gene expression. Molecular and Cellular Biology, 32(17), 3452-3463. https://doi.org/10.1128/MCB. 00526-12

Simpson, I. A., Carruthers, A., and Vannucci, S. J. (2007). Supply and demand in cerebral energy metabolism: the role of nutrient transporters. Journal of Cerebral Blood Flow and Metabolism: Official Journal of the International Society of Cerebral Blood Flow and Metabolism, 27(11), 
1766-1791. https://doi.org/10.1038/sj.jcbfm. 9600521

Sochocka, M., Koutsouraki, E. S., Gasiorowski, K., and Leszek, J. (2013). Vascular oxidative stress and mitochondrial failure in the pathobiology of Alzheimer's disease: a new approach to therapy. CNS and Neurological Disorders Drug Targets, 12(6), 870-881.

Soták, M., Sumová, A., and Pácha, J. (2014). Crosstalk between the circadian clock and the cell cycle in cancer. Annals of Medicine, 46(4), 221-232. https://doi.org/10.3109/07853890.2014.892296

Stobart, J. L., and Anderson, C. M. (2013). Multifunctional role of astrocytes as gatekeepers of neuronal energy supply. Frontiers in Cellular Neuroscience, 7, 38. https://doi.org/10.3389/fncel. 2013.00038

St-Pierre, J., Lin, J., Krauss, S., Tarr, P. T., Yang, R., Newgard, C. B., and Spiegelman, B. M. (2003). Bioenergetic analysis of peroxisome proliferatoractivated receptor gamma coactivators 1alpha and 1beta (PGC-1alpha and PGC-1beta) in muscle cells. The Journal of Biological Chemistry, 278(29), 26597-26603. https://doi.org/10.1074/ jbc.M301850200

Struck, L. K., Rodnitzky, R. L., and Dobson, J. K. (1990). Circadian fluctuations of contrast sensitivity in Parkinson's disease. Neurology, 40(3 Pt 1), 467-470.

Strum, J. C., Shehee, R., Virley, D., Richardson, J., Mattie, M., Selley, P., ... Roses, A. (2007). Rosiglitazone induces mitochondrial biogenesis in mouse brain. Journal of Alzheimer's Disease: $J A D, 11(1), 45-51$.

Sun, Q., Chen, X., Ma, J., Peng, H., Wang, F., Zha, X., ... Zhang, H. (2011). Mammalian target of rapamycin up-regulation of pyruvate kinase isoenzyme type M2 is critical for aerobic glycolysis and tumor growth. Proceedings of the National Academy of Sciences of the United States of America, 108(10), 4129-4134. https:// doi.org/10.1073/pnas.1014769108

Takada, I., Kouzmenko, A. P., and Kato, S. (2009). Wnt and PPARgamma signaling in osteoblastogenesis and adipogenesis. Nature Reviews. Rheumatology, 5(8), 442-447. https://doi.org/10.1038/nrrheum. 2009.137

Thomas, B., and Beal, M. F. (2007). Parkinson's disease. Human Molecular Genetics, 16 Spec No. 2, R183-194. https://doi.org/10.1093/hmg/ddm159 Tsunemi, T., Ashe, T. D., Morrison, B. E., Soriano, K. R., Au, J., Roque, R. A. V., ... La Spada, A. R. (2012). PGC-1a rescues Huntington's disease proteotoxicity by preventing oxidative stress and promoting TFEB function. Science Translational
Medicine, 4(142), 142ra97. https://doi.org/ 10.1126/scitransImed.3003799

Vallée, A., Guillevin, R., and Vallée, J.-N. (2017). Vasculogenesis and angiogenesis initiation under normoxic conditions through $\mathrm{Wnt} / \beta$-catenin pathway in gliomas. Reviews in the Neurosciences. https://doi.org/10.1515/revneuro-2017-0032

Vallée, A., and Lecarpentier, Y. (2016). Alzheimer Disease: Crosstalk between the Canonical Wnt/ Beta-Catenin Pathway and PPARs Alpha and Gamma. Frontiers in Neuroscience, 10, 459. https://doi.org/10.3389/fnins.2016.00459

Vallée, A., Lecarpentier, Y., Guillevin, R., and Vallée, J.-N. (2017a). Aerobic Glycolysis Hypothesis Through WNT/Beta-Catenin Pathway in Exudative Age-Related Macular Degeneration. Journal of Molecular Neuroscience: MN, 62(3-4), 368-379. https://doi.org/10.1007/s12031-017-0947-4

Vallée, A., Lecarpentier, Y., Guillevin, R., and Vallée, J.-N. (2017b). Effects of cannabidiol interactions with $W n t / \beta$-catenin pathway and PPARY on oxidative stress and neuroinflammation in Alzheimer's disease. Acta Biochimica Et Biophysica Sinica, 49(10), 853-866. https:// doi.org/10.1093/abbs/gmx073

Vallée, A., Lecarpentier, Y., Guillevin, R., and Vallée, J.-N. (2017c). Interactions between TGF- $\beta 1$, canonical WNT/ $\beta$-catenin pathway and PPAR $Y$ in radiation-induced fibrosis. Oncotarget, 8(52), 90579-90604. https://doi.org/10.18632/oncotarget. 21234

Vallée, A., Lecarpentier, Y., Guillevin, R., and Vallée, J.-N. (2017d). PPARY agonists: Potential treatments for exudative age-related macular degeneration. Life Sciences. https://doi.org/ 10.1016/j.Ifs.2017.09.008

Vallée, A., Lecarpentier, Y., Guillevin, R., and Vallée, J.-N. (2017e). Thermodynamics in Gliomas: Interactions between the Canonical WNT/BetaCatenin Pathway and PPAR Gamma. Frontiers in Physiology, 8, 352. https://doi.org/10.3389/fphys. 2017.00352

Vallée, A., Lecarpentier, Y., Guillevin, R., and Vallée, J.-N. (2018a). Aerobic glycolysis in amyotrophic lateral sclerosis and Huntington's disease. Reviews in the Neurosciences. https://doi.org/ 10.1515/revneuro-2017-0075

Vallée, A., Lecarpentier, Y., Guillevin, R., and Vallée, J.-N. (2018b). Demyelination in Multiple Sclerosis: Reprogramming Energy Metabolism and Potential PPARy Agonist Treatment Approaches. International Journal of Molecular Sciences, 19(4). https://doi.org/10.3390/ijms19041212

Vallée, A., Lecarpentier, Y., Guillevin, R., and Vallée, J.-N. (2018c). Reprogramming energetic 
metabolism in Alzheimer's disease. Life Sciences, 193, 141-152. https://doi.org/10.1016/j.Ifs. 2017.10 .033

Vallée, A., Lecarpentier, Y., and Vallée, J.-N. (2017). Thermodynamic Aspects and Reprogramming Cellular Energy Metabolism during the Fibrosis Process. International Journal of Molecular Sciences, 18(12). https://doi.org/10.3390/ ijms 18122537

Vallée, A., Lecarpentier, Y., and Vallée, J.-N. (2019). Hypothesis of Opposite Interplay Between the Canonical WNT/beta-catenin Pathway and PPAR Gamma in Primary Central Nervous System Lymphomas. Current Issues in Molecular Biology, 31, 1-20. https://doi.org/10.21775/cimb.031.001

Vallée, A., Lévy, B. L., and Blacher, J. (2018). Interplay between the renin-angiotensin system, the canonical WNT/ $\beta$-catenin pathway and PPARY in hypertension. Current Hypertension Reports, 20(7), 62. https://doi.org/10.1007/s11906-018-0860-4

Vallée, A., Vallée, J.-N., Guillevin, R., and Lecarpentier, Y. (2017). Interactions Between the Canonical WNT/Beta-Catenin Pathway and PPAR Gamma on Neuroinflammation, Demyelination, and Remyelination in Multiple Sclerosis. Cellular and Molecular Neurobiology. https://doi.org/ 10.1007/s10571-017-0550-9

Vallée, A., Vallée, J.-N., and Lecarpentier, Y. (2018). PPARY agonists: potential treatment for autism spectrum disorder by inhibiting the canonical WNT/ $\beta$-catenin pathway. Molecular Psychiatry. https://doi.org/10.1038/s41380-018-0131-4

Valvezan, A. J., and Klein, P. S. (2012). GSK-3 and Wnt Signaling in Neurogenesis and Bipolar Disorder. Frontiers in Molecular Neuroscience, 5, 1. https://doi.org/10.3389/fnmol.2012.00001

Videnovic, A., and Golombek, D. (2013). Circadian and sleep disorders in Parkinson's disease. Experimental Neurology, 243, 45-56. https:// doi.org/10.1016/j.expneurol.2012.08.018

Videnovic, A., and Willis, G. L. (2016). Circadian system - A novel diagnostic and therapeutic target in Parkinson's disease? Movement Disorders: Official Journal of the Movement Disorder Society, 31(3), 260-269. https://doi.org/10.1002/mds. 26509

Videnovic, A., and Zee, P. C. (2015). Consequences of Circadian Disruption on Neurologic Health. Sleep Medicine Clinics, 10(4), 469-480. https:// doi.org/10.1016/j.jsmc.2015.08.004

Wang, H.-M., Zhao, Y.-X., Zhang, S., Liu, G.-D., Kang, W.-Y., Tang, H.-D., ... Chen, S.-D. (2010). PPARgamma agonist curcumin reduces the amyloid-beta-stimulated inflammatory responses in primary astrocytes. Journal of Alzheimer's
Disease: JAD, 20(4), 1189-1199. https://doi.org/ 10.3233/JAD-2010-091336

Wang, N., Yang, G., Jia, Z., Zhang, H., Aoyagi, T., Soodvilai, S., ... Yang, T. (2008). Vascular PPARgamma controls circadian variation in blood pressure and heart rate through Bmal1. Cell Metabolism, 8(6), 482-491. https://doi.org/ 10.1016/j.cmet.2008.10.009

Wang, Q., Liu, Y., and Zhou, J. (2015). Neuroinflammation in Parkinson's disease and its potential as therapeutic target. Translational Neurodegeneration, 4, 19. https://doi.org/10.1186/ s40035-015-0042-0

Wang, X., Sirianni, A., Pei, Z., Cormier, K., Smith, K., Jiang, J., ... Friedlander, R. M. (2011). The melatonin MT1 receptor axis modulates mutant Huntingtin-mediated toxicity. The Journal of Neuroscience: The Official Journal of the Society for Neuroscience, 31(41), 14496-14507. https:// doi.org/10.1523/JNEUROSCI.3059-11.2011

Weishaupt, J. H., Bartels, C., Pölking, E., Dietrich, J., Rohde, G., Poeggeler, B., ... Ehrenreich, H. (2006). Reduced oxidative damage in ALS by high-dose enteral melatonin treatment. Journal of Pineal Research, 41(4), 313-323. https://doi.org/ 10.1111/j.1600-079X.2006.00377.x

Wenz, T., Diaz, F., Spiegelman, B. M., and Moraes, C. T. (2008). Activation of the PPAR/PGC-1alpha pathway prevents a bioenergetic deficit and effectively improves a mitochondrial myopathy phenotype. Cell Metabolism, 8(3), 249-256. https://doi.org/10.1016/j.cmet.2008.07.006

Wiedau-Pazos, M., Wong, E., Solomon, E., Alarcon, M., and Geschwind, D. H. (2009). Wnt-pathway activation during the early stage of neurodegeneration in FTDP-17 mice. Neurobiology of Aging, 30(1), 14-21. https://doi.org/10.1016/ j.neurobiolaging.2007.05.015

Wood-Kaczmar, A., Gandhi, S., Yao, Z., Abramov, A. Y., Abramov, A. S. Y., Miljan, E. A., ... Wood, N. W. (2008). PINK1 is necessary for long term survival and mitochondrial function in human dopaminergic neurons. Plos One, 3(6), e2455. https://doi.org/10.1371/journal.pone.0002455

Wu, D., and Pan, W. (2010). GSK3: a multifaceted kinase in Wnt signaling. Trends in Biochemical Sciences, 35(3), 161-168.

$\mathrm{Wu}$, Y.-H., and Swaab, D. F. (2005). The human pineal gland and melatonin in aging and Alzheimer's disease. Journal of Pineal Research, 38(3), 145-152. https://doi.org/10.1111/j. 1600-079X.2004.00196.x

Xu, C., Wang, J., Zhu, T., Shen, Y., Tang, X., Fang, L., and Xu, Y. (2016). Cross-Talking Between PPAR and WNT Signaling and its Regulation in 
Mesenchymal Stem Cell Differentiation. Current Stem Cell Research and Therapy, 11(3), 247-254.

Yang, G., Jia, Z., Aoyagi, T., McClain, D., Mortensen, R. M., and Yang, T. (2012). Systemic PPARy deletion impairs circadian rhythms of behavior and metabolism. PloS One, 7(8), e38117. https://doi.org/10.1371/journal.pone. 0038117

Yang, S.-H., Li, W., Sumien, N., Forster, M., Simpkins, J. W., and Liu, R. (2015). Alternative mitochondrial electron transfer for the treatment of neurodegenerative diseases and cancers: Methylene blue connects the dots. Progress in Neurobiology. https://doi.org/10.1016/j.pneurobio. 2015.10.005

Yang, Xiaoming, Wood, P. A., Ansell, C. M., Ohmori, M., Oh, E.-Y., Xiong, Y., ... Hrushesky, W. J. M. (2009). Beta-catenin induces beta-TrCP-mediated PER2 degradation altering circadian clock gene expression in intestinal mucosa of ApcMin/+ mice. Journal of Biochemistry, 145(3), 289-297. https:// doi.org/10.1093/jb/mvn167

Yang, Xiaoyong, Downes, M., Yu, R. T., Bookout, A. L., He, W., Straume, M., ... Evans, R. M. (2006). Nuclear receptor expression links the circadian clock to metabolism. Cell, 126(4), 801-810. https://doi.org/10.1016/j.cell.2006.06.050

Yasuniwa, Y., Izumi, H., Wang, K.-Y., Shimajiri, S., Sasaguri, Y., Kawai, K., ... Kohno, K. (2010). Circadian disruption accelerates tumor growth and angio/stromagenesis through a Wnt signaling pathway. PloS One, 5(12), e15330. https://doi.org/ 10.1371/journal.pone.0015330

Yin, F., Boveris, A., and Cadenas, E. (2014). Mitochondrial energy metabolism and redox signaling in brain aging and neurodegeneration. Antioxidants and Redox Signaling, 20(2), 353-371. https://doi.org/10.1089/ars.2012.4774
Yue, X., Lan, F., Yang, W., Yang, Y., Han, L., Zhang, A., ... Kang, C. (2010). Interruption of $\beta$-catenin suppresses the EGFR pathway by blocking multiple oncogenic targets in human glioma cells. Brain Research, 1366, 27-37. https://doi.org/ 10.1016/j.brainres.2010.10.032

Yujnovsky, I., Hirayama, J., Doi, M., Borrelli, E., and Sassone-Corsi, P. (2006). Signaling mediated by the dopamine D2 receptor potentiates circadian regulation by CLOCK:BMAL1. Proceedings of the National Academy of Sciences of the United States of America, 103(16), 6386-6391. https:// doi.org/10.1073/pnas.0510691103

Zhang, H. H., Lipovsky, A. I., Dibble, C. C., Sahin, M., and Manning, B. D. (2006). S6K1 regulates GSK3 under conditions of mTOR-dependent feedback inhibition of Akt. Molecular Cell, 24(2), 185-197. https://doi.org/10.1016/j.molcel. 2006.09.019

Zhang, H.-M., and Zhang, Y. (2014). Melatonin: a well-documented antioxidant with conditional prooxidant actions. Journal of Pineal Research, 57(2), 131-146. https://doi.org/10.1111/jpi.12162

Zhang, K., Zhang, J., Han, L., Pu, P., and Kang, C. (2012). Wnt/beta-catenin signaling in glioma. Journal of Neuroimmune Pharmacology: The Official Journal of the Society on Neurolmmune Pharmacology, 7(4), 740-749. https://doi.org/ 10.1007/s11481-012-9359-y

Zhou, T., Zu, G., Zhang, X., Wang, X., Li, S., Gong, $X ., \ldots$ Zhao, J. (2016). Neuroprotective effects of ginsenoside Rg1 through the $\mathrm{Wnt} / \beta$-catenin signaling pathway in both in vivo and in vitro models of Parkinson's disease. Neuropharmacology, 101, 480-489. https://doi.org/10.1016/ j.neuropharm.2015.10.024 
